OPEN ACCESS

Edited by:

José Antonio Teixeira University of Minho, Portugal

Reviewed by:

Ana C. Pinheiro,

Center for Biological Engineering, School of Engineering, University of Minho, Portugal

Alejandra Acevedo-Fani, Riddet Institute, New Zealand

*Correspondence:

Ravishankar Rai Vittal raivitta/@gmail.com

Specialty section

This article was submitted to Sustainable Food Processing,

a section of the journal

Frontiers in Sustainable Food Systems

Received: 23 November 2018 Accepted: 07 October 2019 Published: 13 November 2019

Citation: Aswathanarayan JB and Vittal RR (2019) Nanoemulsions and Their Potential Applications in Food Industry.

Front. Sustain. Food Syst. 3:95 doi: 10.3389/fsufs.2019.00095

\section{Nanoemulsions and Their Potential Applications in Food Industry}

\author{
Jamuna Bai Aswathanarayan and Ravishankar Rai Vittal*
}

Department of Studies in Microbiology, University of Mysore, Mysore, India

Nanoemulsions have small droplet size and are kinetically stable colloidal systems. They have enhanced functional properties in comparison to conventional emulsions. The composition and structure of the nanoemulsions can be controlled for the encapsulation and effective delivery of bioactive lipophilic compounds. Nanoemulsions have potential application in the food industry for the delivery of nutraceuticals, coloring and flavoring agents, and antimicrobials. The nanoemulsion formulations of active ingredients can be used for developing biodegradable coating and packaging films to enhance the quality, functional properties, nutritional value, and shelf life of foods. This review focuses on preparation of food grade nanoemulsions using high-energy methods and low-energy approaches and their characterization for physical properties, stability, and microstructure. The application of nanoemulsion formulations for sustainable food processing and improving the delivery of functional compounds, such as colorants, flavoring agents, nutraceuticals, and preservatives or antimicrobial agents in foods has been discussed.

Keywords: nanoemulsions, encapsulation, bioactive compounds, functional foods, nutraceuticals

\section{INTRODUCTION}

Emulsions are defined as the dispersion of two immiscible liquids, with the spherical droplets forming the dispersed phase, whereas the liquid surrounding it forms the continuous phase (Tadros et al., 2004; McClements et al., 2007; Acosta, 2009). The commonly used liquids to form emulsion are water and oil. The oil droplets dispersed in an aqueous phase are known as oil-in-water $(\mathrm{o} / \mathrm{w})$ emulsions. These emulsion systems can be used for the delivery of hydrophobic active substances. The water droplets dispersed in oil are called the water-in-oil (w/o) emulsions and are used for the delivery of hydrophilic compounds. Multiple emulsion systems can also be developed such as the water-in-oil-in-water $(\mathrm{w} / \mathrm{o} / \mathrm{w})$ and oil-in-water-in-oil (o/w/o) emulsions. The w/o/w emulsions are made of large oil droplets, containing water droplets dispersed in an aqueous phase. Whereas, in o/w/o emulsion system, water droplets containing oil droplets are dispersed in an oil phase. Bicontinuous nanoemulsion contains microdomains of oil and water-interdispersed within the system (Garti and Benichou, 2004; Weiss et al., 2006).

Emulsions are categorized as coarse emulsions, microemulsions and nanoemulsions based on their droplet size and stability (Komaiko and McClements, 2016). In Table 1, the various types of emulsion systems have been mentioned. However, there is some ambiguity regarding their description based on size. The coarse emulsions are also known as conventional emulsions or macroemulsions. They have particle size of diameter $>200 \mathrm{~nm}$ range and are thermodynamically metastable. They break down over time due to various destabilizing factors. Conventional emulsions are optically turbid as the dimension of the droplets is similar to that of the wavelength of light and hence, scatters the incident light and appears opaque. The 
TABLE 1 | Emulsion types: physicochemical properties, stability, and preparation methods.

\begin{tabular}{|c|c|c|c|}
\hline & $\begin{array}{l}\text { Emulsion/coarse } \\
\text { emulsion/macroemulsion }\end{array}$ & Microemulsion & Nanoemulsion \\
\hline Size & $1-100 \mu \mathrm{M}$ & $10-100 \mathrm{~nm}$ & $<200 \mathrm{~nm}$ \\
\hline Thermodynamic Stability & Metastable & Stable & Metastable \\
\hline Kinetic stability & Stable & Unstable & Stable \\
\hline Optical property & Turbid & Transparent & Transparent/slightly translucent \\
\hline Polydispersity & High (>40\%) & Low $(<10 \%)$ & Low (<10-20\%) \\
\hline Preparation method & High and low energy methods & Low energy methods & High and Low energy methods \\
\hline Effect of temperature and $\mathrm{pH}$ & $\begin{array}{l}\text { Stable to temperature and } \mathrm{pH} \\
\text { changes }\end{array}$ & $\begin{array}{l}\text { Effected by changes in } \\
\text { composition, temperature and } \mathrm{pH}\end{array}$ & $\begin{array}{l}\text { Stable to temperature and } \mathrm{pH} \\
\text { changes }\end{array}$ \\
\hline
\end{tabular}

droplets in microemulsions are $<100 \mathrm{~nm}$ in size and are thermodynamically stable. However, their stability is affected by even slight variations in environmental conditions such as composition and temperatures. Microemulsion forms spontaneously as its free energy is lower than its phase-separated components. They are optically transparent as the particle size is lesser than the wavelength and weakly scatters light (Anton and Vandamme, 2011). The nanoemulsions have droplet dimensions similar to the microemulsions ranging from $<200$ and in some cases $<100 \mathrm{~nm}$ (Saifullah et al., 2016). Similar to conventional emulsions, nanoemulsions are thermodynamically metastable as phase separation occurs over time. However, nanoemulsions are conferred with kinetic stability as there is no gravitational separation and droplet aggregation due to the reduced attractive force between the small sized droplets (McClements and Rao, 2011). The nanoemulsions unlike the thermodynamically stable microemulsions are not affected by physical and chemical variations including temperature and $\mathrm{pH}$. They require less amount of surfactants for their preparation. The droplet size of nanoemulsion apart from determining its optical property and stability, also influences its rheological and release behavior. Hence, the nanoemulsions are more suitable than microemulsions for various applications.

The present review focuses on the increased application of nanoemulsions in the food industries for sustainable food processing and packaging. The nanoemulsions have the ability to encapsulate functional compounds and active ingredients including antioxidants and nutraceuticals. They are also useful in the controlled release of flavor compounds in foods (Velikov and Pelan, 2008; McClements and Rao, 2011; Ines et al., 2015). Nanoemulsion encapsulation of bioactive compounds increase its solubility, controlled release and absorption in the gastrointestinal tract, and absorption through cells (Chen et al., 2006; McClements and Rao, 2011). Nanoemulsion based edible nanocoatings containing flavor and coloring ingredients, antioxidants, enzymes, antimicrobials, and antibrowning agents can be used to coat foods such as meats, dairy products such as cheese, fresh produce, and fresh cuts including fruit and vegetables and confectionaries to improve their shelf life. The nanoemulsion coatings can also prevent moisture and gas exchange, minimize moisture loss and oxidation of foods (Azeredo et al., 2009; Rojas-Graü et al., 2009; Salvia-Trujillo et al., 2015; Donsi, 2018).

\section{COMPOSITION OF NANOEMULSIONS}

Nanoemulsion formulation requires the use of two immiscible liquids and an emulsifier. One of the immiscible liquids must be oleaginous and the other aqueous in nature, and they make up the dispersed and aqueous phase. The o/w and w/o nanoemulsion consists of a core-shell structure. For example, in an $\mathrm{o} / \mathrm{w}$ nanoemulsion system the amphiphillic shell is made of surface-active molecules, whereas the lipophilic core contains non-polar molecules. The oil phase in a nanoemulsion is made of triacylglycerols, diacylgycerols, monoacylglycerols, and free fatty acids. Non polar essential oils, mineral oils, lipid substitutes, waxes, weighting agents, oil-soluble vitamins, and various lipophilic components are also used as oil phase. The viscosity, refractive index, density, phase behavior, and interfacial tension of the oil phase components influences the formation, stability, and functional properties of nanoemulsion (Tadros et al., 2004; Wooster et al., 2008; McClements and Rao, 2011). However, the long-chain triacylglycerols are preferred for nanoemulsion formulation due to their low cost, availability, functional, and nutritional attributes (Witthayapanyanon et al., 2006). The aqueous phase of a nanoemulsion is made of polar solvent and a cosolvent. It determines the polarity, rheology, phase behavior, interfacial tension, and ionic strength of nanoemulsion. The polar solvent generally used is water, whereas carbohydrates, protein, alcohol, and polyols are used as cosolvents (Saxena et al., 2017). The aqueous phase and oil phase can breakdown due to Ostwald ripening (increase in mean droplet size over time), flocculation, coalescence, and gravitational separation (Kabalnov, 2001; McClements and Rao, 2011). This can be prevented by adding a stabilizer agent to nanoemulsion. The stabilizers distribute on a particle and can form either a monolayer, multilayer, and solid particulate nanoemulsions. Some of the stabilizers used are emulsifiers, weighting agents, ripening retarders, and texture modifiers.

Emulsifiers are surface active molecules and commonly used stabilizers in nanoemulsion preparation to protect small droplets. They reduce the interfacial tension resulting in formation of small and stable nanoemulsions. The emulsifiers also prevent collision and coalescence between the droplets and increases the kinetic stability of the nanoemulsions (Mason et al., 2006). The emulsifiers can be cationic, anionic, nonionic, and zwitterionic in nature. Some examples of emulsifiers 
are small-molecule surfactants, phospholipids, proteins, and polysaccharides (McClements, 2004; Kralova and Sjöblom, 2009). Even polymers like polyvinyl alcohol are used as emulsifiers. The surfactants can be either ionic or non-ionic in nature. Ionic surfactant prevents droplets aggregation by electrostatic repulsion, whereas non-ionic surfactants reduce aggregation by steric hindrances, thermal fluctuation interactions, and hydration (McClements, 2004; Silva et al., 2015). For o/w emulsion preparations, hydrophile-lipophile balance values $>10$ are used as a criterion for selecting emulsifiers. For example, proteins insoluble in oils are used as emulsifiers for $\mathrm{o} / \mathrm{w}$ nanoemulsion preparation. Two or more emulsifiers have also been used together in nanoemulsion formulation for their synergistic effect. On using both hydrophilic and lipophilic (or cosurfactant) emulsifiers, a significant decrease in surface tension has been observed (Shakeel et al., 2009; Qadir et al., 2016). Similarly, block copolymers that are soluble only in the dispersed phase can decrease surface tension (Tadros et al., 2004). However, some surfactants have found to be irritants, which limit their application in foods. This has resulted in the formulation of w/o emulsions without surfactants (Glatter and Glatter, 2013). Such surfactant-free nanoemulsions can be prepared by cooling the continuous phase below its melting temperature, which leads to formation of kinetically stable emulsion made up of lyotropic liquid crystalline nanostructure (Ridel et al., 2015; Duffus et al., 2016; Chen et al., 2018). Weighting agents are used in nanoemulsion preparation to impede the gravitational forces and reduce sedimentation and creaming. Weighting agents such as ester and damar gum are used in o/w emulsion as their density matches with that of the oil phase surrounding aqueous phase. Ripening retarders have hydrophobic action which helps in retarding the ripening (Schuch et al., 2014). The generally used ripening retards such as mineral oils and long chain triacyl glycerols prevent diffusion of smaller oil molecules through the aqueous phase to form larger molecules (Sonneville-Aubrun et al., 2004). The ripening inhibitors have low water solubility and cause entropy of mixing for balancing the curvature effects (Wooster et al., 2008; Li et al., 2009). The texture modifiers used in the nanoemulsions interact only with the aqueous phase and increase its viscosity by thickening it or turning it into a gel. They prevent the movement of oil droplets and impart creaminess and thickness to aqueous phase. Some of the commonly used texture modifiers are biopolymers including gums, vegetable proteins, and polysaccharides (Imeson, 2011). In Table 2, the commonly used food grade emulsifiers and various stabilizing agents have been mentioned.

In the recent years, there is an increased interest in the use of food-grade stabilizers for the preparation of nanoemulsions (Rayner et al., 2014). Pickering stabilization has superior stability in comparison to conventional surfactant-stabilized nanoemulsions. The pickering particles form a dense layer at the oil and water interface and by steric mechanism prevent droplet flocculation and coalescence (Duffus et al., 2016). The three main prerequisites for efficient pickering stabilization have been identified. The particle should be in $200 \mathrm{~nm}-1 \mu \mathrm{m}$ size range with sufficient particle charge and should have affinity to emulsion continuous phase (Duffus et al., 2016). A number of food grade particles including proteins, polysaccharides, and flavonoids have been investigated for pickering nanoemulsion preparation. However, colloidal lipid particles have shown to be the most promising pickering stabilizers in $\mathrm{O} / \mathrm{W}$ emulsions as they are able to impart good physical stability. These are simple to prepare with tunable microstructure, and can be used to prepare nanoemulsions using high pressure homogenization method and cross flow microfluidic device (Schroder et al., 2017, 2018).

\section{PROPERTIES OF NANOEMULSIONS AND DESTABILIZING MECHANISM}

The optical properties of nanoemulsion are important for their application in food industry. Based on their droplet size nanoemulsions are optically transparent or faintly turbid. Their opacity is expressed in terms of turbidity $(\tau)$ and characterized by transmission measurements (McClements and Rao, 2011). The mean particle size and narrow particle-size distribution influences the opacity of nanoemulsions (Wooster et al., 2008). The rheological properties of nanoemulsions modify the texture of foods (Quemeda and Berli, 2002; Walstra, 2003; Genovese et al., 2007). The relative droplet size is known to influence the rheological properties of nanoemulsions. For example, beverages have low viscosity and the nanoemulsions used for their preparation should have droplets which do not increase the overall viscosity (McClements and Rao, 2011).

The physicochemical stability of nanoemulsions is characterized as kinetically stable systems as these breaks down over time due to destabilizing physical mechanisms (gravitational separation, flocculation, coalescence) and chemical instability (Figure 1). Gravitational separation is due to different relative densities between the dispersed and continuous phases and results in creaming or sedimentation. Formation of crystalline lipids or small oil droplets causes sedimentation in an o/w nanoemulsions. Similarly, creaming in nanoemulsions occurs due to large particle size as the movement of droplets is influenced by gravity. In nanoemulsions with particle diameter $<70 \mathrm{~nm}$, the Brownian motion effects movement of smaller particles and prevents creaming (Walstra, 2003; McClements and Rao, 2011). Droplet aggregation such as flocculation or coalescence is less in nanoemulsions due to their relatively small particle size (Tadros et al., 2004). In nanoemulsions, colloidal interactions is related to their droplet size and occurs due to the attractive interactions (van der Waals and hydrophobic) and repulsive interactions (electrostatic and stearic) between two adjacent droplets (McClements, 2005; McClements and Rao, 2011). Ostwald ripening occurs as the droplet size increases over time due to diffusion or movement of solubilized oil molecules from small droplets to large droplets through dispersed phase (Kabalnov, 2001; McClements and Rao, 2011). The decrease in droplet size causes an increase in aqueous-solubility of oil present within a spherical droplet resulting in large number of solubilized oil molecules. This solubilized oil molecules move to larger droplets leading to a gradual increase in the droplet size. The aqueous solubility of oil phase determines the stability of a nanoemulsion to Ostwald ripening (Kabalnov and Shchukin, 
TABLE 2 | Food grade stabilizing agents used in nanoemulsions preparations for food related applications.

\begin{tabular}{|c|c|c|c|}
\hline Stabilizing agent & Compound & Concentration & References \\
\hline \multirow[t]{11}{*}{$\begin{array}{l}\text { Emulsifier (Non-ionic } \\
\text { surfactant) }\end{array}$} & $\begin{array}{l}\text { Lecithin (Phospholipid) and } \\
\text { Tween } 80\end{array}$ & $\begin{array}{l}\text { Lecithin at } 1 \text { wt. } \% \text { with oil phase and Tween } 80 \text { at } 2 \\
\text { wt. } \% \text { with aqueous phase }\end{array}$ & Tan et al., 2016 \\
\hline & Lecithin and Tween 80 & Lecithin/Tween 80 at 0.3 molar ratio & Kumar et al., 2017 \\
\hline & $\begin{array}{l}\text { PEG } 40 \text { hydrogenated castor oil; } \\
\text { Sorbitan monoleate }\end{array}$ & Oil:surfactant at 2:1 & Nantarat et al., 2015 \\
\hline & Tween 20 & With aqueous phase at 0.75 wt. $\%$ & Severino et al., 2015 \\
\hline & & With both phases at 1 wt. $\%$ & Artiga-Artigas et al., 2017 \\
\hline & Tween 20 and Span 80 & $\begin{array}{l}\text { Tween } 20 \text { and aqueous phase at 1wt.\% } \\
\text { Span } 80 \text { and oil phase at } 4 \text { wt. } \%\end{array}$ & Alexandre et al., 2016 \\
\hline & Tween 80 & Mixing with both phases at 3 wt. $\%$ & Acevedo Fani et al., 2015 \\
\hline & & Mixing with organic phase at 7.5 wt. $\%$ & Chen et al., 2017 \\
\hline & & Mixing with oil phase at 4.5 wt. $\%$ & Gahruie et al., 2017 \\
\hline & Tween 80 and Span 80 & $\begin{array}{l}\text { Tween } 80 \text { with aqueous phase at } 1.25 \text { wt. } \% \text { and } \\
\text { Span } 80 \text { with oil phase at } 3.75 \text { wt. } \%\end{array}$ & Dammak et al., 2017 \\
\hline & Sucrose monosterate & Mixing with aqueous phase at 0.5 wt. $\%$ & Ruiz-Montañez et al., 2017 \\
\hline \multirow[t]{2}{*}{ Emulsifier (Anionic) } & Sodium dodecyl sulfate & with aqueous phase at 2.5 wt. $\%$ & $\begin{array}{l}\text { Qian and McClements, } \\
2011\end{array}$ \\
\hline & & with aqueous phase at 3 wt. $\%$ & Lee et al., 2013 \\
\hline \multirow[t]{3}{*}{ Emulsifier (Amphiphilic) } & Whey protein isolate & With aqueous phase at 4 wt.\% & Hebishy et al., 2015 \\
\hline & Egg yolk powder & $\begin{array}{l}\text { Mixing with water as continuous phase at } 3 \text { wt.\% } \\
\text { for W/O/W emulsion formation }\end{array}$ & Schuch et al., 2014 \\
\hline & & Mixed with aqueous phase at 3 wt. $\%$ & Lee et al., 2013 \\
\hline \multirow[t]{4}{*}{ Plasticizer } & Glycerol & $\begin{array}{l}\text { Mixing with nanoemulsion and biopolymer at } \\
\text { glycerol/biopolymer ratio of } 0.3\end{array}$ & Alexandre et al., 2016 \\
\hline & & Mixing with oil phase at 2\% (v/v) & Alexandre et al., 2016 \\
\hline & & $\begin{array}{l}\text { Mixing with biopolymer at } 30 \text { wt.\% and then with } \\
\text { emulsion solutions }\end{array}$ & Dammak et al., 2017 \\
\hline & Poly(ethylene glycol) & Mixing with nanoemulsion at $0.2 \%(\mathrm{w} / \mathrm{v})$ & Otoni et al., 2014b \\
\hline Ripening retardant & Sodium chloride & $\begin{array}{l}\text { Mixing with aqueous phase at } 0.5 \text { wt. } \% \text { for W/O/W } \\
\text { inner emulsion }\end{array}$ & Schuch et al., 2014 \\
\hline Texture modifier & Sodium alginate & $\begin{array}{l}\text { Addition at } 1 \% \text { before coarse emulsion formation by } \\
\text { homogenizer (Ultra-Turrax) at 11,000 rpm for } 2 \\
\text { minutes at room temperature }\end{array}$ & Artiga-Artigas et al., 2017 \\
\hline
\end{tabular}

1992). Chemical degradation of nanoemulsions occurs due to oxidation and hydrolysis. The large specific surface area of nanoemulsions makes it prone to chemical degradation. The opacity of nanoemulsions also play a role in chemical stability. The clear nanoemulsions with small droplets get easily degraded by UV or visible light due to transparency (Dickinson, 1992; Friberg et al., 2004; McClements, 2005).

\section{PREPARATION OF NANOEMULSIONS}

The nanoemulsions have numerous droplets which increases the surface area. Therefore, large amount of energy is required to create extra surface. Thus, nanoemulsion formation is not spontaneous and requires energy input. The energy required for the formation of nanoemulsions $(\Delta G)$ is estimated by the expression, $\Delta \mathrm{G}=\Delta \mathrm{A} \gamma-\mathrm{T} \Delta \mathrm{S}$, where $\Delta A$ is increase in interfacial area, $\gamma$ is surface tension and $T \Delta S$ is the entropy of dispersion (Tadros et al., 2004; Schramm, 2006).

Nanoemulsions can be prepared by either high energy or low energy methods. Its size is dependent on the constituents, operating conditions, and preparation methods. The emulsification process involves break up of droplets into smaller ones, adsorption of surfactants, and collision of droplets. The adsorption kinetics also affects the stability and droplet size of nanoemulsions (Silva et al., 2015). The high energy methods, involve the use of mechanical devices which disrupts oil phase for it to interact with water phase and form smaller oil droplets. The excessive stress generated by the mechanical device disrupts oil phase. Most of the food industries use high energy methods to prepare oilin-water nanoemulsions (Gutiérrez et al., 2008). In the low energy methods, nanoemulsions are prepared by altering the temperature or composition of the oil-water system and the energy input is from the chemical potential of the constituents (Bouchemal et al., 2004).

Major factors involved in nanoemulsion preparation is to achieve significantly low interfacial tension $(<10-3 \mathrm{mN} / \mathrm{m})$ at the oil/water interface which requires the use of appropriate surfactant. The surfactant also helps in stabilizing droplets produced at low interfacial tension. Fluidity at the interface 


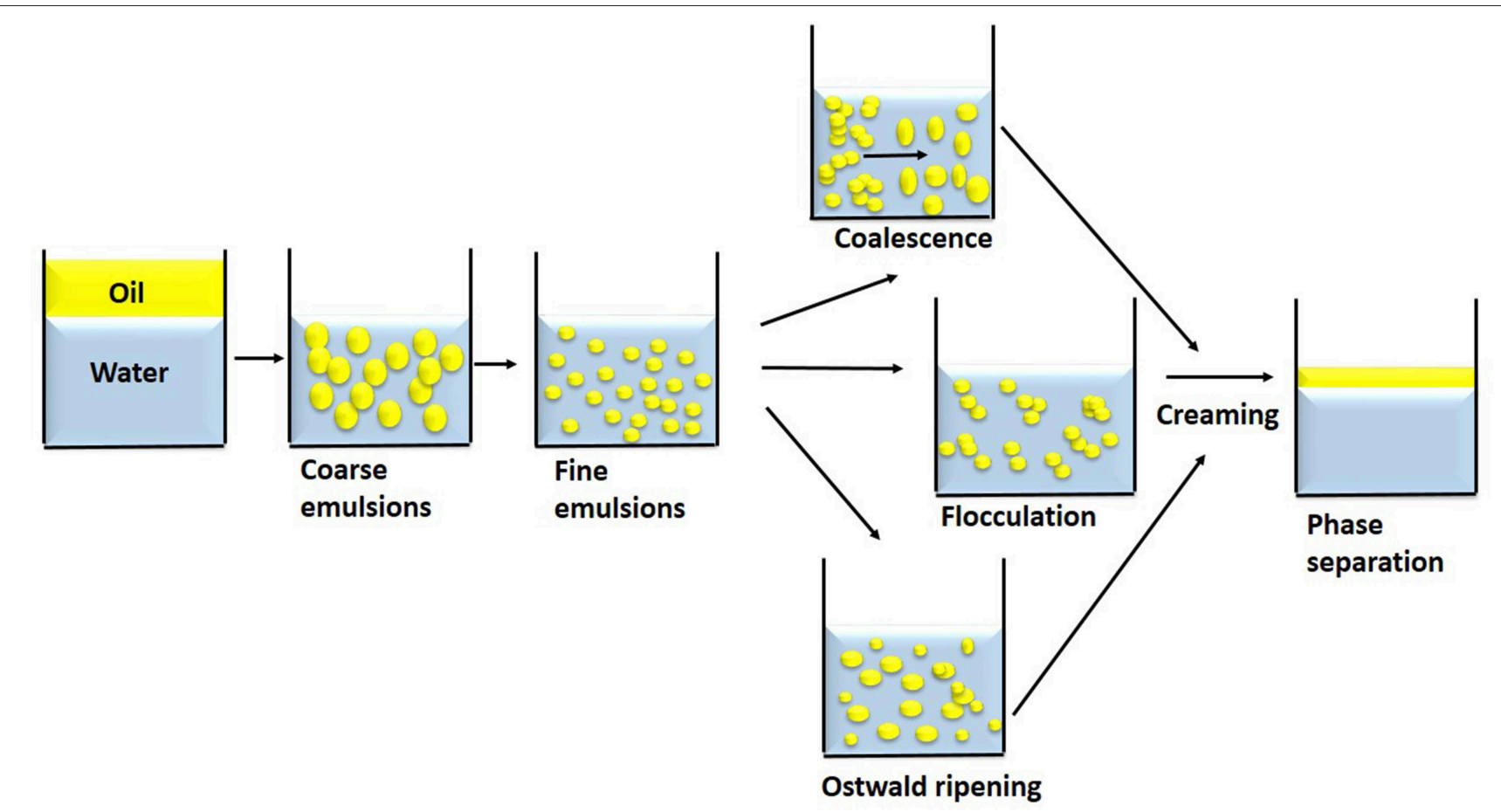

FIGURE 1 | Nanoemulsion formation and destabilizing mechanisms. Coalescence involves droplets combining; flocculation involves droplet aggregating but do not combine; droplets grow in size through Ostwald ripening. This destabilizing mechanism results in creaming and phase separation.

is another important factor for stimulating nanoemulsion formation (Bhosale et al., 2014).

\section{High Energy Methods}

The high energy methods involve the use of a mechanical device such as high pressure valve homogenizers, microfluidizers and ultrasonicators (Figure 2). These devices are used to apply highly disruptive force for disrupting dispersed phase into tiny droplets of nanoemulsions (Maali and Hamed Mosavian, 2013).

\section{High Pressure Valve Homogenization Method}

The device used in the high pressure valve homogenization (HPVH) method, includes a positive displacement pump, pressure valve, and chambers for homogenization and interaction. The coarse emulsion is sucked into the homogenization chamber by the suction stroke of the pump. The homogenization chamber can be a simple orifice plate, colliding jet or radial diffuser assemblies (Stang et al., 2001; Donsì et al., 2009). High pressure of upto $300 \mathrm{MPa}$ generated in the chamber during delivery stroke causes the coarse emulsion to be pushed out through small orifice of micrometric size by the homogenizer valve. At this stage, the factors such as turbulence, shear stress, and cavitation disrupts coarse emulsions into very finer droplets (Tesch et al., 2003; Schultz et al., 2004). Further, the fine droplets get stabilized in the interaction chamber. Thus, in the high pressure homogenization, emulsification occurs in two stages. Firstly, disruption of dispersed phase results in tiny droplet formation with increased surface area in the homogenization chamber. In the second stage, the addition of emulsifier molecules and its adsorption at the newly formed interfaces causes stabilization of droplets in the interaction chamber. Repeated disruption and stabilization results in production of higher number of tiny droplets. The reduction in interfacial tension and maintaining low viscosity ratio of dispersed and continuous phase decreases droplet size (Tadros et al., 2004; Lee and McClements, 2010). An increase in concentration of emulsifier in nanoemulsions has also shown to decrease droplet diameter (Windhab et al., 2005). The emulsifiers can also reduce instability of re-coalescence of droplets after disruption. This is by adsorbing at the interface of the droplets to form a protective layer thereby, preventing the coalescence. However, the adsorption process should occur at a faster rate than coalescence (Jafari et al., 2008). But the organoleptic constraints and regulations, limits the use of higher concentrations of emulsifier in food emulsion. Studies have shown that small-molecule emulsifiers such as Tween 20 and sodium dodecyl sulfate (SDS), produce smaller droplet sizes than larger molecules emulsifiers such as proteins (Anton et al., 2008). High pressure homogenization cannot be applied for viscous lipids (Witthayapanyanon et al., 2006).

Thus, high-pressure homogenization efficiently breaks down droplets and increases stability (Schultz et al., 2004). The ease of applicaion, scalability, reproducibility, and high throughput makes high pressure valve homogenization technique, highly suitable for producing nanoemulsions in food industries (Schubert and Engel, 2004). The high-pressure homogenization preparation of the nanoemulsion is more efficient and gives better quality (Liu et al., 2019). High pressure homogenization method 


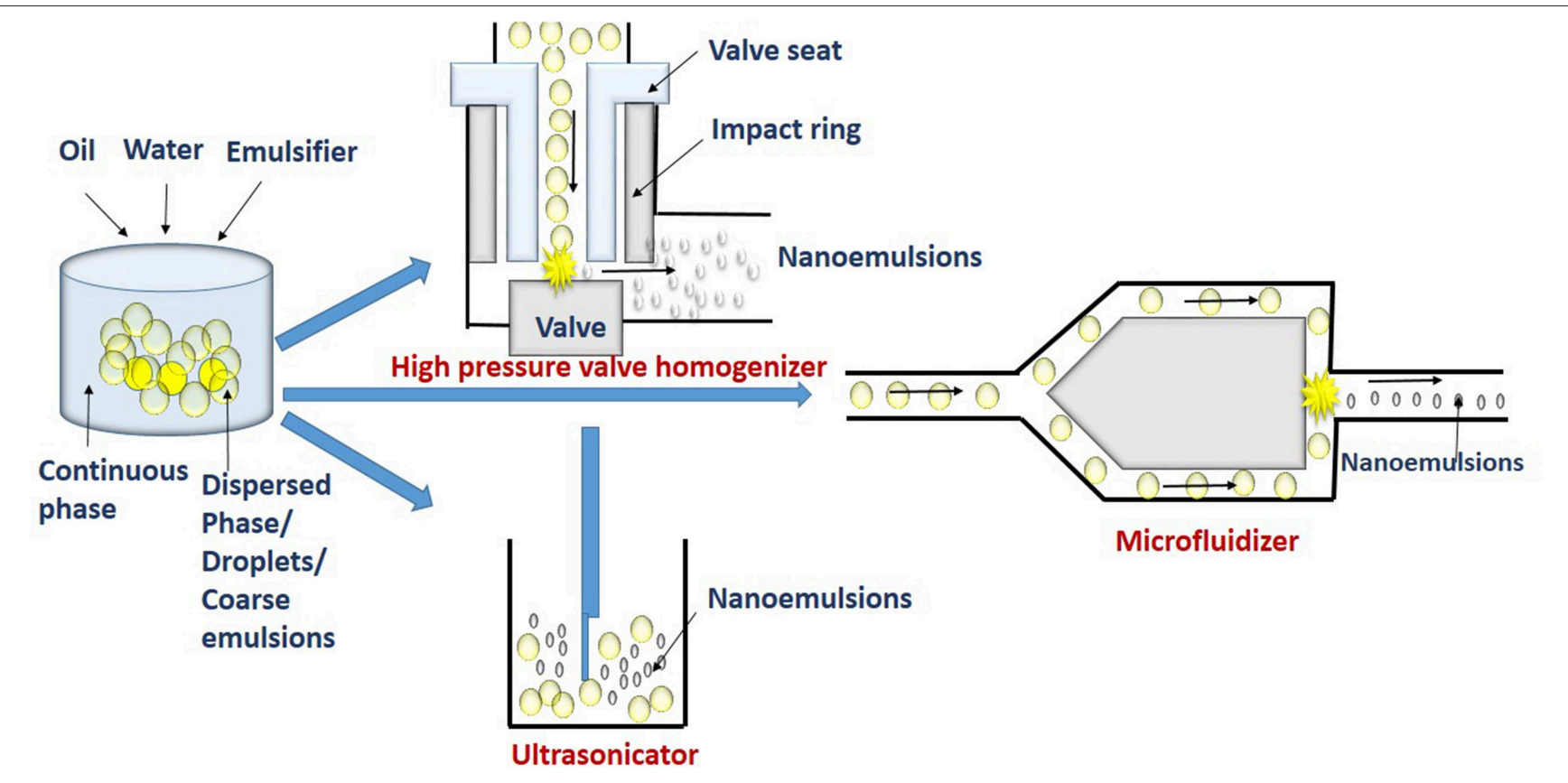

FIGURE 2 | High energy methods such as high pressure homogenization (HPH), microfluidizer, and ultrasonication break macroemulsions into smaller droplets.

was used to prepare nanoemulsions of carvacrol, mandarin, bergamot, and lemon. Primary emulsions of essential oils were subjected to five cycles of high pressure homogenization at $200 \mathrm{MPa}$ to obtain nanoemulsions of $133-200 \mathrm{~nm}$. The nanoemulsion of carvacrol showed significant growth inhibitory activity against Escherichia coli O157:H7 and Salmonella Typhimurium. Carvacrol nanoemulsion was incorporated into modified chitosan to form a bioactive coating. It increased the shelf life of green beans stored at $4^{\circ} \mathrm{C}$ for upto 13 days (Severino et al., 2015). The o/w nanoemulsions of jackfruit pulp extract rich in carotenoids was obtained by high-pressure homogenization (400-800 bar). The nanoemulsion was stabilized by sucrose monostearate emulsifier and exhibited a longer stability in its antioxidant activity during storage at $4^{\circ} \mathrm{C}$. Nanoemulsions with a high stability were produced at 800 bar. The antioxidant activity of a jackfruit pulp extract was protected by nanoemulsion (Ruiz-Montañez et al., 2017). Lycopene nanodispersions with a narrow polydispersity index and good stability for application in beverages were developed using homogenization process. Homogenization pressure of 500 bar reduced the particle size and lycopene concentration significantly, while homogenization pressure of 700-900 bar resulted in large particle sizes with high dispersibility. Homogenization pressure also effected zeta potential and turbidity of the lycopene nanodispersion (Shariffa et al., 2017). High pressure homogenization of 50-300 $\mathrm{MPa}$ was used to obtain stable lentil nanoemulsions. Stable lentil nanoemulsions was obtained with homogenizer pressure above $200 \mathrm{MPa}$ and the best stability was achieved at $300 \mathrm{MPa}$. Highpressure homogenization decreased nanoemulsion viscosity under all conditions (Tabilo-Munizaga et al., 2019). Highpressure homogenizers were initially used in dairy industry for fat globule disruption in dairy applications. However, now they are extensively used for food processing applications as nanoemulsion for delivering supplemented nutrients and as a preservation technique. It was assumed that friction heat generated in the homogenizer may cause degradation of temperature sensitive nutrients. Recent studies have shown that no thermal degradation occurs in valve due to the short residence time (3-40 ms) (Håkansson, 2019).

\section{Microfluidization Method}

The basic principle of emulsification by microfluidization is similar to the high pressure valve homogenizer, except for the use of a special microchannel having dimensions in the range of 50$300 \mu \mathrm{m}$ to form droplets in the microfluidization method. In this technique, the coarse emulsion is pumped with high pressure (up to $270 \mathrm{MPa}$ ) at the inlet through a microchannel at velocities of $400 \mathrm{~m} / \mathrm{s}$. The channels at the downstream gets split into two small branches to form $\mathrm{Y}$ or $\mathrm{T}$ junction. These branches reconnect at far downstream to an interaction channel. In the interaction chamber, the coarse emulsions from two steams impinges on each other with very high velocity. Thus, the impulsive forces generated in two streams and shear rate as high as $107 \mathrm{~s}^{-1}$ are sufficient for disrupting and forming fine emulsions in the interaction channel (Souto et al., 2005). The process is repeated for more than two cycles to increase emulsification time and pressure. Thus, the size of nanoemulsion depends on the disruption of droplets and its recoalescence. However, the addition of a fast-adsorbing emulsifier and increasing the viscosity of continuous phases can reduce the recoalescence rate (Jafari et al., 2007; Bae et al., 2009; Mao et al., 2010). 
Microfluidization was used to obtain nanoemulsions of thyme, lemongrass, and sage oil dispersed in sodium alginate solution. The technique reduced the average droplet size of nanoemulsions and resulted in $\zeta$-potentials between -41 and $-70 \mathrm{mV}$. Sage essential oil nanoemulsions showed good film property such as higher transparency, water vapor resistance, and flexibility. Edible films of thyme essential oil had strong antimicrobial effect on E. coli. Microfluidizers could be used to prepare nanoemulsions with active ingredients for the formation of edible films, with different physical and functional properties (Acevedo Fani et al., 2015). Nanoemulsion of ginger essential oil was produced by microfluidization. Edible films reinforced with montmorillonite was activated with ginger essential oil nanoemulsion. The incorporation of nanoemulsions improved characteristics and antioxidant activity of montmorillonite films. The incorporation of montmorillonite and nanoemulsion into gelatin-based films increased the thickness and decreased the solubility in water, moisture content and superficial hydrophobicity of films (Alexandre et al., 2016). Dual-channel microfluidization have also been used for efficiently producing label-friendly nanoemulsions from natural emulsifiers. The emulsifiers either amphiphilic biopolymers (whey protein and gum arabic) or biosurfactants (quillaja saponinand soy lecithin) were used to prepare corn oil-in-water nanoemulsions. The use of dual-channel microfluidization resulted in production of nanoemulsions with the mean particle diameter decreasing with increasing emulsifier concentration and homogenization pressure. Using this technique, whey protein isolate and quillaja saponin were more effective at forming nanoemulsions of fine droplets than gum arabic and soy lecithin. Low amount of emulsifier was required and smaller droplets were produced (Bai et al., 2016). Dual-channel microfluidization proved to be an efficient method for continuously producing carotenoid-loaded nanoemulsions from natural emulsifiers. It was used to prepare $\mathrm{o} / \mathrm{w}$ nanoemulsions of $\beta$-carotene. Two types of natural emulsifier, quillaja saponins and whey protein isolate were used for nanoemulsions preparation by this novel homogenization method. At 4 and $25^{\circ} \mathrm{C}$, the nanoemulsions remained physically stable throughout 14 days storage. At $55^{\circ} \mathrm{C}$, small amount of droplet aggregation occurred in saponin nanoemulsions. Thus, microfluidization technique can be used to encapsulate $\beta$-carotene and improve its water dispersibility and chemical stability in foods (Luo et al., 2017). Microfluidization was used to produce small sized fish oil nanoemulsion as fish oil is rich in polyunsaturated fatty acids (PUFAs). Coarse emulsion had a droplet size of $1.5 \mu \mathrm{m}$, while microfluidization produced smaller droplet size $(\geq 200 \mathrm{~nm})$. Zeta potential values increased around $-30 \pm 2 \mathrm{mV}$. Nanoemulsions with an average droplet size around $200 \mathrm{~nm}$ were prepared with $144 \mathrm{MPa}$ and two passes of microfluidization. Thus, microfluidization could be used to develop nanoemulsions with better absorption in the digestive tract (García-Márquez et al., 2017). Microfluidization has also been used to encapsulate high nutritional value oils, such as high-oleic palm oil (Ricaurte et al., 2016). o/w nanoemulsions of high-oleic palm oil was obtained by microfluidization wherein, $1-20 \% \mathrm{w} / \mathrm{w}$ of the oil could be easily encapsulated. Stable nanoemulsions of
$163 \mathrm{~nm}$ drop size and zeta potential of -29.7 were obtained (Ricaurte et al., 2016).

The limitations of the microfluidization techniques are increased droplet size as a result of coalescence due to longer time involved in emulsification and the use of high pressure increases the temperature of nanoemulsions. However, in comparison to other homogenization techniques, the efficiency of droplet disruption by microfluidization technique is high and results in formation of fine droplets with uniform size.

\section{Ultrasonication Method}

In this technique, the ultrasonic agitation by sound waves with more than $20 \mathrm{kHz}$ frequency breaks coarse droplets into nanoemulsions. Sound waves applied by sonotrode produce mechanical vibration and acoustic cavitation, and with the collapse of cavitations, strong shock waves generated break the coarse droplets (Behrend et al., 2000). The acoustic and shock waves create high pressure and turbulence which collapse the droplets. At high frequency (mega $\mathrm{Hz}$ ), nanoemulsions can even be prepared without using an emulsifier (Kamogawa et al., 2004; Jafari et al., 2007).

The device consists of an ultrasonic chamber having an ultrasonic probe. The disruptive forces created by the ultrasonic probe in combination with cavitation, turbulence, and interfacial waves breaks the coarse emulsions flowing in the ultrasonic chamber to fine nanoemulsions (Kentish et al., 2008). Similarly, bench-top sonicator is used for the production of nanoemulsions at small scale. The piezoelectric crystal probe in the sonicator generates intense pressure waves. An optimum level of input energy is required for sonification to achieve smallest droplet diameter. On increasing the sonication time, there is also an increase in input energy which tends to disrupt higher number of droplets and decrease their size (Jafari et al., 2007). The other factors which influence nanoemulsion formation are concentration of emulsifier, viscosity ratio of dispersed and continuous phase and the amplitudes of applied waves (Nakabayashi et al., 2011). It was observed that nanoemulsions prepared by high intensity ultrasonication from flax seed oil and nonionic surfactant (Tween 40) had droplet radius below $70 \mathrm{~nm}$ (Kentish et al., 2008). Similarly, high-intensity ultrasound has also been used to obtain nanoemulsions with droplet radius of $20 \mathrm{~nm}$. These were prepared using grade emulsifiers including sunflower oil, Tween 80, and Span 80 (Leong et al., 2009). The increased ultrasonification time and decreased surfactant concentration resulted in nanoemulsions with droplet diameter of $29.3 \mathrm{~nm}$. The nanoemulsions were prepared with basil oil and nonionic emulsifier (Tween 80 and water) and had a high intrinsic stability with ultrasonication time of $15 \mathrm{~min}$ (Ghosh et al., 2013).

High intensity ultrasound $(150 \mathrm{~W})$ has been used to prepare nanoemulsions of essential oils of Zataria multiflora. The bioactivity of the essential oil was increased by nanoemulsion. Further, increase in the antibacterial activity could be observed by decreasing the nanoemulsion droplet size. The small sized nanoemulsions could be easily incorporated in the basil seed gum films. Increased nanoemulsion concentration in the film matrix effected the microstructure of the film and improved 
its mechanical properties. The films also showed significant antimicrobial activity against potential foodborne pathogens (Gahruie et al., 2017). Nanoemulsions of resveratrol and resveratrol-cyclodextrin inclusion complex in a phospholipid stabilized nanoemulsion has been prepared by ultrasonic emulsification. The resveratrol nanoemulsion and inclusion complex nanoemulsion had an average size of 20 and $24 \mathrm{~nm}$, respectively. The nanoemulsions developed by ultrasonication had a good loading and release efficiency. The nanoemulsion prevented degradation of resveratrol on exposure to UV irradiation (365 nm) (Kumar et al., 2017).

Studies have been carried out to compare the efficiency of high pressure homogenization and ultrasonication to develop the nanoemulsions of capsaicin (oleoresin capsicum). Capsaicin nanoemulsions obtained by high pressure homogenization were optically translucent with $79 \%$ efficiency and significant antimicrobial activity. However, nanoemulsions prepared by ultrasonication had good physical properties and smaller droplet size of $65 \mathrm{~nm}$ (Akbas et al., 2018).

\section{Low Energy Methods}

The low-energy methods, use the energy input from chemical potential of the components to from nanoemulsions. The nanoemulsions form spontaneously at oil and water phase interface by gentle mixing of the components. The spontaneous emulsification can be controlled by two methods. One of the methods is to change temperature without altering composition. The other method is to keep the temperature constant and vary the compositions and interfacial properties. Thus, nanoemulsion formation by low energy methods depends on physicochemical properties such as temperature, composition, and solubility (Anton and Vandamme, 2009). The low energy methods involved in the nanoemulsion production are phase inversion temperature (PIT), phase inversion composition (PIC), and solvent diffusion method. These methods involve minimal energy generation, and thereby prevent the degradation of heat labile compounds.

\section{Phase Inversion Temperature Method}

The method uses phase invasion property of the molecules, wherein the emulsifiers change their hydrophilicity or lipophilicity as a function of temperature at fixed composition (Figure 3). Depending on the hydration of the polar heads of the non-ionic surfactants, they change their spontaneous curvature (Anton and Vandamme, 2009). At low temperature, oil-in-water emulsion is formed. Whereas, at high temperature, water-in-oil emulsion is formed as the solubility of emulsifier in water decreases with increase in temperature. The phase inversion temperature is the temperature at which there is transition from oil-in-water to water-in-oil emulsion (McClements and Rao, 2011). At a particular temperature, the curvature of emulsifier layer becomes zero and solubility of emulsifier becomes approximately equal in water and oil phase. At this stage, there is no tendency to form either oil-in-water or waterin-oil nanoemulsion and constituents form a bicontinuous or lamellar liquid crystalline system. At higher temperature, the surfactant layer becomes concave with negative curvature due to dehydration of hydrophilic nonionic surfactant. The solubility of surfactant in oil is more (lipophilic) than water phase and thus water-in-oil nanoemulsion is formed. Temperature at which there is a conversion of oil-in-water to water-in-oil emulsion is termed as phase inversion temperature (PIT) (Pathak, 2017).

It is also to be noted that surface tension decreases with increase in temperature and fine emulsions with small sized droplets are formed. At PIT, these small droplets are not stable as they try to coalesce and form macroemulsions. If a large amount of emulsifier is used to reduce instability, droplets do not coalesce immediately, and some liquid crystal structure forms at PI temperature (Salager et al., 2004). Thus, although it is possible to form emulsions near PIT, they are very unstable. To produce stable and fine oil-in-water nanoemulsions, a cooling process is required and final nanoemulsions are required to be preserved at a temperature far below PIT (Liew et al., 2010). In addition, if emulsions formed near PIT are rapidly cooled or heated, kinetically stable emulsions with small droplet size and narrow size distribution can be produced. PIT can be determined by noting down the change in different properties of nanoemulsions such as conductivity, viscosity, and turbidity (Rao and McClements, 2010).

Phase inversion temperature method was used to prepare cinnamon oil nanoemulsions. Cinnamon oil, non-ionic surfactant, and water were heated above the phase inversion temperature of the system. It was rapidly cooled with continuous stirring resulting in spontaneous formation of small oil droplets with mean droplet diameter of $101 \mathrm{~nm}$. The cooling-dilution method increased stability of the nanoemulsions for 31 days at $4^{\circ} \mathrm{C}$ or $25^{\circ} \mathrm{C}$ (Chuesiang et al., 2018). The effect of phase inversion temperature method on biological activity of cinnamon oil nanoemulsions has been studied. The surfactant concentration effected the antimicrobial activity of the cinnamon oil nanoemulsions. The increase in surfactant concentration from 15 to $20 \mathrm{wt} \%$ enhanced the antimicrobial activity of nanoemulsion in comparison to nanoemulsions with lower surfactant concentration (10 wt\%) or with bulk cinnamon oil (Chuesiang et al., 2019).

\section{Phase Inversion Composition Method}

In this technique, varying the composition of constituents changes the hydrophilic-lipophilic behavior of emulsifier (Figure 3). On adding salt to an oil-in-water nanoemulsion with ionic emulsifier, the electric charge of surfactant changes and it turns to water-in-oil emulsion system (Maestro et al., 2008). Similarly, a water-in-oil emulsion having high salt content can be converted to oil-in-water by diluting with water (Liew et al., 2010). This technique has low cost, does not require the use of organic solvents and it has high thermodynamic stability (Shakeel et al., 2009). It is difficult to use phase inversion method for highly hydrophobic compounds (Witthayapanyanon et al., 2006).

Phase inversion composition method has been used to prepare food-grade nanoemulsions enriched with vitamin $\mathrm{E}$ acetate with a mean particle diameter of $40 \mathrm{~nm}$. This method was more effective at producing nanoemulsions at high surfactant concentration than microfluidization technique. However, the technique was not favorable for nanoemulsions preparations with 


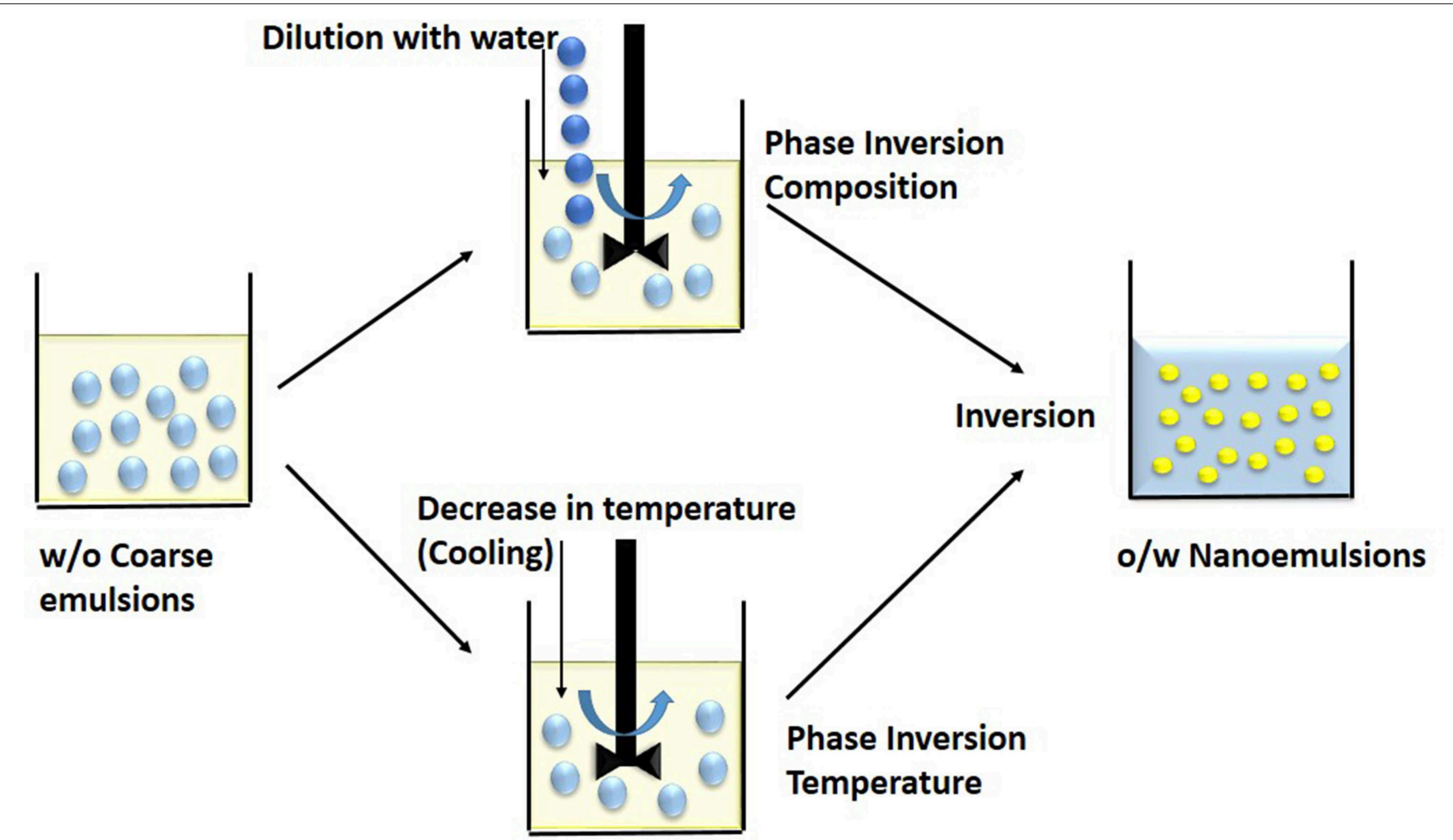

FIGURE 3 | Low energy methods involves breakdown of coarse w/o macroemulsions into nanoemulsions during phase inversion. In the Phase Inversion Composition technique, dilution by water induces a phase inversion while in the Phase Inversion Temperature method, cooling or decrease in temperature induces a phase inversion.

label-friendly surfactants, such as Quillaja saponin, whey protein, casein, and sucrose monoesters (Mayer et al., 2013).

\section{Spontaneous Emulsification Method}

In this technique, spontaneous emulsions are formed on mixing water and oil together with an emulsifier by gentle stirring at a particular temperature (Figure 4). The mixing of phases by gentle magnetic stirring causes the emulsifier to enter the aqueous phase leading to increase of oil-water interfacial area resulting in oil droplet formation (Anton et al., 2008). The excess oil phase is removed by evaporation under reduced pressure (Bouchemal et al., 2004). The drawback of this method is the use of high synthetic surfactants at large scale which is not feasible economically and has regulatory and sensory issues in food industry.

Thus, in the low energy method of nanoemulsion formation, the intrinsic physicochemical properties of surfactants and the oily phase plays a major role and can be easily scaled up. In the high-energy techniques, the size distribution and composition of nanoemulsion can be controlled using mechanical devices, however, there could be degradation of constituents and the production processes cannot be scaled up (Date et al., 2010).

Spontaneous emulsification method has been used to obtain vitamin $\mathrm{E}$ acetate nanoemulsions of droplet diameters $<50 \mathrm{~nm}$ and low polydispersity indexes. Oil phase composition and surfactant-to-emulsion ratio had to be optimized to produce fine droplets. Particle size could also be reduced by increasing the temperature and stirring speed used when the oil/surfactant mixture was added to water (Saberi et al., 2013). Similarly, vitamin $\mathrm{D}$ nanoemulsions have been prepared by spontaneous emulsification. The nanoemulsions with small droplet diameters $<200 \mathrm{~nm}$ that were stable to droplet growth at ambient temperatures but unstable at high temperatures $\left(>80^{\circ} \mathrm{C}\right)$ were obtained. The thermal stability of the nanoemulsions was increased by using a cosurfactant during the formulation (Guttoff et al., 2015). Spontaneous emulsification has been used to prepare fish oil nanoemulsions as these are rich in omega- 3 fatty acids. Transparent nanoemulsions with physical stability at $37^{\circ} \mathrm{C}$ and oxidative stabilities at $55^{\circ} \mathrm{C}$ for 14 days could be prepared (Walker et al., 2015). Cinnamaldehyde has been encapsulated in self-emulsifying emulsion systems. Stable cinnamaldehyde nanoemulsions were achieved only with the addition of mediumchain triglyceride. The encapsulation efficiency of nanoemulsions was $80 \%$ for 1 week and slow release of cinnamaldehyde could be expected. Phase separation occurred after 12 days of storage under $37^{\circ} \mathrm{C}$. Encapsulation efficiency of cinnamaldehyde in nanoemulsions was maintained around $80 \%$ within 1 week (Tian et al., 2016).

The effect of high and low energy approaches on the physicochemical properties of nanodispersions has been evaluated. Solvent displacement and highpressure valve homogenization was used to prepare lutein 


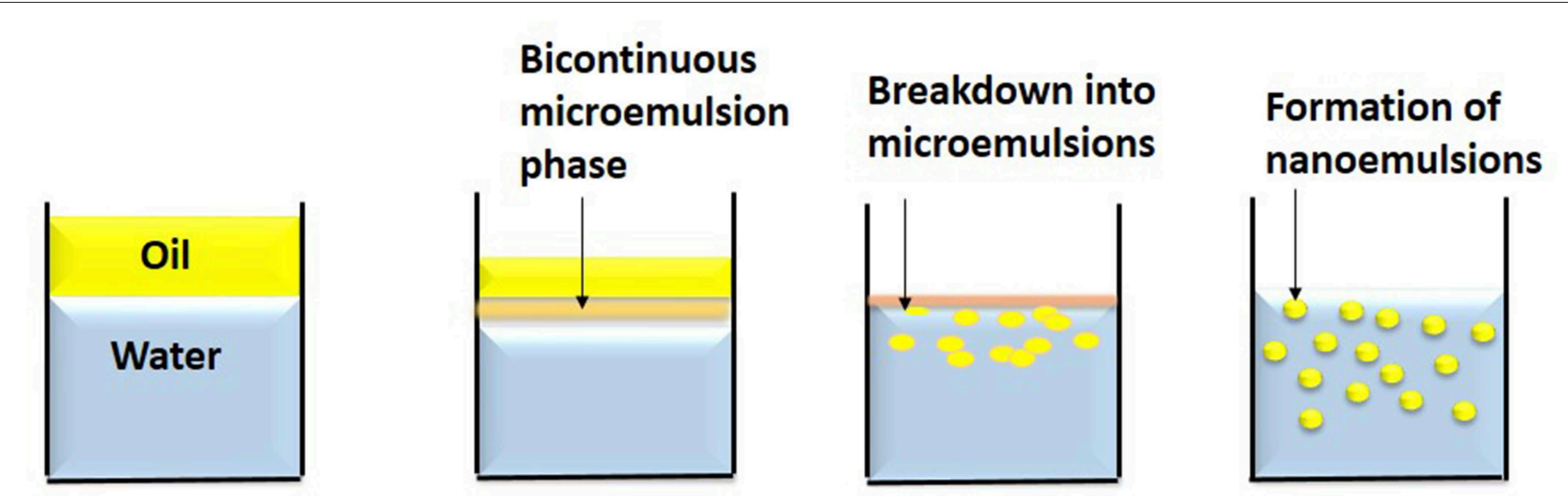

FIGURE 4 | Spontaneous emulsification is a low energy method. In this method, nanoemulsions are formed on mixing water and oil together with an emulsifier by gentle stirring at a particular temperature.

nanodispersions. The particle size and particle size distribution of nanodispersions prepared prepared by both methods were not significantly different. They also had very high lutein retentions (>90\%). Therefore, solvent displacement can also be a good alternative to high-pressure valve homogenization in lutein nanodispersions preparation (Tan et al., 2016).

\section{Novel Nanoemulsion Preparation Techniques}

The conventional nanoemulsification formulation involves the break drown of larger droplets or inversion of solvents. New emulsification approaches are being increasingly developed to increase the range of materials formulations and operating conditions, and to simultaneously lower the production costs.

A bottom-up approach method based on condensation has been developed to create nanoscale emulsions. Water-inoil nanoemulsions are prepared by condensing water vapor on subcooled oil-surfactant solution. The water droplets nucleate at the oil and air interface to spontaneously disperse within the oil. This occurs as a result of the spreading dynamics of oil on water which depends on the oil-surfactant concentration. The nanoemulsions formed using condensation approach have a peak radii of $100 \mathrm{~nm}$. An oil bath is placed in a humid environment with appropriate concentration of surfactant, and on decreasing the temperature below the dew point, water condensation is induced on the oil surface resulting in nanoemulsion formation. The process is simple, rapid, scalable, and energy efficient with potential application in processed foods (Guha et al., 2017).

Pickering nanoemulsions have been developed using the vapor condensation strategy. The use of pickering nanoemulsion overcomes the problems associated with surfactant desorption and Ostwald ripening. The high energy approach prevents adsorption of the particles on the droplets whereas, the low energy approach cannot be used to produce pickering nanoemulsions. The vapor condensation method used for pickering nanoemulsion preparation is a single step process and has several advantages over the conventional techniques such as use of low concentration of nanoparticles (Kang et al., 2018).

\section{CHARACTERIZATIONS OF NANOEMULSIONS}

The physiochemical properties of nanoemulsions such as physical properties, stabilities, rheological property, and microstructure have to be characterized for its application in foods as these properties are known to influence the final texture, taste, flavor, and stability of foods. The basic physical properties of nanoemulsion are particle size, size distribution, charge, and lipid crystallinity.

Particle structure and size distribution of nanoemulsions is measured by dynamic light scattering (DLS) and small-angle Xray scattering (SAXS), non-invasive techniques. DLS technique measures size distribution of small particles or droplets in suspensions in the range of $3 \mathrm{~nm}-5 \mu \mathrm{m}$. DLS records the intensity fluctuations that occur as a result of change of relative spatial location due to Brownian motion of small particles over time when light is scattered by particles (Mason et al., 2006; Fryd and Mason, 2012). In the DLS technique, the size distribution profiles of nanoemulsions is observed as a single and narrow peak as it is monodisperse (Yun Zhang, 2003). DLS measurement utilizes the "Mie theory" mathematical model to determine the scattering pattern of the droplets contained in the emulsion. DLS data is observed as plot of particle concentration and its size (Mcclements, 2007). DLS can also be used to evaluate the stability of nanoemulsions in various external conditions.

Small-angle X-ray scattering (SAXS)/small-angle neutron scattering (SANS) is used to characterize the colloidal particles for its shape, size, and nanostructure (Gradzielski, 2008). The 
SAXS pattern is a function between intensity and scattering vector and obtained at low angles (typically $0.1-10^{\circ}$ ), whereas SANS uses short wavelength $(\lambda<10 \AA)$ to measure neutron scattering length density of nanoemulsions (Mason et al., 2006).

Particle charge or the electrical surface charge of emulsions is determined by measuring the zeta potential ( $\zeta$-potential). $\zeta$ potential is the electro-kinetic potential in nanoemulsions. The particles with surface charge on dispersion in liquid phase attract the ions of opposite charges which form a firm attachment known as stern layer. The electrical charge on the droplet surface affects the interactions between emulsion droplets and in turn the stability of nanoemulsions. The nanoemulsions having high absolute value of zeta potential (negative or positive, commonly above 30) are electrically stabilized, and those with low zeta potential coagulate (Mcclements, 2007; Mohanraj and Chen, 2007).

Lipid crystallinity of nanoemulsions is measured using a thermo-analytical technique, differential scanning calorimetry (DSC). The technique measures the crystalline temperature differences of pure oil and oil in emulsion and thus assesses the influence of oil crystallization on the stability of the nanoemulsion (Thanasukarn et al., 2004; Rafanan, 2013). The impurities present in the oil used for emulsion causes crystal formation and nucleation, which in turn affects the stability of nanoemulsion. The percentage of destabilized fat in the emulsions can be calculated using the DSC instrument. It measures the area under the non-emulsified enthalpy peaks during a cooling cycle, and divides it by the area under all of the enthalpy peaks. However, as the oil is dispersed into small droplets, the interfacial layer reduces the nucleation growth of oil crystal (Mcclements, 2007).

Nuclear magnetic resonance (NMR)-based techniques have also been used to study the types, structure, and diffusion properties of components in nanoemulsions (Acharya and Hartley, 2012; Hathout and Woodman, 2012). One of the NMR techniques, the Fourier transform pulsed gradient spin echo (FT-PGSE) technique measures self-diffusion coefficients of oil, water, and surfactant molecules at a time. It is also useful in determining the connectivity in emulsions and the PGSE helps to know the phase transient between the droplet emulsion phase and bicontinuous emulsion (Gradzielski, 2008).

Rheology of nanoemulsions is measured using shear device which gives the value of apparent viscosity and the dependent relationship between apparent viscosity and shear stress. The dynamic oscillation methods are used to evaluate the viscoelastic properties of emulsions. The stable emulsions flow curves have a constant value of apparent viscosity at low shear rates $\left(\sim 0.01 \mathrm{~s}^{-1}\right)$ and a strong shear thinning follows at high shear rates (Sharma et al., 2010). The rheological properties of nanoemulsions are affected by the surfactants used, shape, and number density of the droplets, and interactions between the constituent droplets (Acharya and Hartley, 2012). Use of cosurfactants has shown to weaken the interactions between emulsifier and the anionic surfactant, resulting in reduced viscosity (Howe and Pitt, 2008).

Microstructure characterization of nanoemulsions is carried out using microscopy imaging techniques. Electron microscopy (EM) techniques is used for the visualization of the microstructure of nanoemulsions at a resolution of $<5 \mathrm{~nm}$ (Acharya and Hartley, 2012; Silva et al., 2012). Transmission electron microscopy (TEM) which has a resolution of $(0.2 \mathrm{~nm})$ has been used to image materials and biological samples (Luykx et al., 2008; Silva et al., 2012). It has also been used to study the morphology and structure of the nanoemulsions (Bouchemal et al., 2004; Inugala et al., 2015). However, sample preparation for TEM uses high-energy electron beam which can cause structural damage to the materials (Luykx et al., 2008). This problem can be overcome by the use of cryogenic preparation (cryo-TEM) and freeze-fracture (FFTEM) techniques. Cryo-TEM is effective in characterizing the structure of microemulsions (Spernath et al., 2009). The FFTEM provides detailed structure of bicontinuous nanoemulsions and droplets within discontinuous nanoemulsions (Krauel et al., 2007; Acharya and Hartley, 2012). Scanning electron microscope (SEM) is used to characterize materials in the nanometer to micrometer scale for microstructure morphology and chemical composition (Goldstein et al., 2003; Ferreira et al., 2015). SEM uses narrow electron beam to provide surface structures. Hence, SEM is used to obtain surface structure of oil droplets of nanoemulsion (Silva et al., 2012). SEM can be used to process large amounts of materials at low magnification, and high-resolution images can be obtained at higher magnification (Luykx et al., 2008). The drawbacks associated with SEM are high cost, use of high vacuum and high sample conductivity. Surfactants present in the sample can also interfere with SEM imaging as it causes coating on the particle surfaces (Luykx et al., 2008). Atomic force microscopy (AFM) microscopy is used for structural characterization of nanoemulsion. It detects the changes of force between a shape probe and an immobilized sample and produces a high-resolution 3-D profile of the sample surface (Preetz et al., 2010).

\section{APPLICATION OF NANOEMULSIONS IN FOOD}

The technological limitations of developing functional foods is the low solubility, stability, and bioavailability of the bioactive compounds. Most of the bioactive food ingredients are susceptible to degradation during food processing and oxidative deterioration during storage (Xianquan et al., 2005; Shahidi and Zhong, 2010). Certain bioactives have low solubility but rapid metabolism which reduces its bioavailability, whereas some are volatile and sensitive to processing conditions (McClements and Li, 2010; Jin et al., 2016). These challenges can be overcome by the use of nanoemulsions to encapsulate bioactive compounds for their use in food matrix. The encapsulation of bioactive compounds in an oil phase or emulsifier ensures it stability, bioavailability, and controlled rate of release ( $\mathrm{McClements} \mathrm{et} \mathrm{al.,}$ 2007). The nanoemulsion based delivery system should have compatibility with food matrix and minimal effect on the organoleptic properties of the food such as its flavor, appearance, and texture. The encapsulation of bioactive compound can protect it from processing conditions and prevent its degradation 
for long duration from temperature, light, $\mathrm{pH}$, and oxidative conditions during storage. The application of nanoemulsion based delivery system for foods requires that the technique is economically feasible for industrial scale production (Borthakur et al., 2016; Pathak, 2017). Table 3 provides an overview of nanoemulsions of bioactive compounds for food applications.

\section{Encapsulation of Flavor and Coloring Agents}

The flavors and coloring compounds used in food have aldehyde, ketone, and esters as functional groups which make them susceptible to oxidative and photolytic degradation. Encapsulation within nanoemulsions of these ingredients can prevent these deleterious effects and enhance its shelf life (Goindi et al., 2016). Citral, a $\alpha, \beta$-unsaturated aldehyde with one additional double bond is an aromatic compound and used as flavors in food and cosmetics. However, its degradation produces off-flavor compounds. Nanoemulsions of citral have been prepared to increase its stability. $\mathrm{O} / \mathrm{W}$ nanoemulsion of citral combined with natural antioxidants such as $\beta$-carotene, tanshinone, and black tea extract had a high chemical stability during storage. The nanoemulsions were prepared with lecithinstabilized palm kernel lipid in $\mathrm{pH} 3$ buffer 1:1 ratio of citral and antioxidants. Encapsulation with antioxidants led to decreased formation of off-flavor compounds, such as $\alpha, p$-dimethylstyrene and $p$-methylacetophenone (Yang et al., 2011). Similarly, O/W nanoemulsion system of citral and ubiquinol-10 $\left(\mathrm{Q}_{10} \mathrm{H}_{2}\right)$ had good chemical stability. The $\mathrm{Q}_{10} \mathrm{H}_{2}$ had a protective effect on citral and prevented its chemical degradation and oxidation. It reduced generation of off-flavor compounds ( $\mathrm{p}$-cresol, $\alpha, \mathrm{p}$ dimethylstyrene, p-methylacetophenone) and lipid degradation products. At $\mathrm{Q}_{10} \mathrm{H}_{2} /$ citral ratio of 1:1, the ubisemiquinone $\left(\mathrm{Q}_{10}\right.$ ${ }^{-}-$)/ubiquinone (Q ${ }_{10}$ ) redox transition was induced, leading to pro-oxidant behavior of $\mathrm{Q}_{10} \mathrm{H}_{2}$ and its ability to maintain citral's stability (Zhao et al., 2013). Gelatin and Tween 20 have been used as emulsifiers to increase the stability of citral from degradation under acidic conditions in the food industry (Tian et al., 2017).

$\beta$-Carotene is a precursor of vitamin A and is used as a natural colorant, and an antioxidant in the food industry. However, it is easily degraded by heat, light, and oxygen. Attempts are being made to increase the stability of $\beta$-carotene toward various processing conditions. $\beta$-carotene nanodispersions prepared by emulsification-evaporation technique have shown an increased stability. Nanoemulsion was prepared by emulsifying organic solution of $\beta$-carotene in aqueous phase containing emulsifier. Stable $\beta$-carotene nanodispersions were produced with weighted mean diameter ranging from 60 to $140 \mathrm{~nm}$ (Tan and Nakajima, 2005a). O/W $\beta$-carotene nanodispersions prepared using nonionic emulsifier polyglycerol esters of fatty acids (PGEs) having mean diameter of 85-132 nm showed improved physicochemical properties and physical stability. PGE decaglycerol monolaurate $\left(10 \mathrm{~g} \mathrm{~kg}^{-1}\right)$ having high glycerol polymerization could be used for highly stable $\beta$-carotene nanodispersions (Tan and Nakajima, 2005b). Protein-stabilized $\beta$-carotene nanodispersions prepared using emulsification-evaporation had a mean particle size of $17 \mathrm{~nm}$. The emulsifier sodium caseinate, at a high concentration reduced particle size and improved the polydispersity of the nanodispersions. The $\beta$-carotene nanodispersions had high $\zeta$ potential of $-27 \mathrm{mV}$ at $\mathrm{pH} 7$ and thus were stable against particle aggregation (Chu et al., 2007). O/W $\beta$-carotene nanoemulsions prepared using Tween 20 as emulsifier by high pressure homogenization had mean diameters from 132 to $184 \mathrm{~nm}$. Only $25 \%$ of $\beta$-carotene in the nanoemulsions degraded after 4 weeks of storage at 4 and $25^{\circ} \mathrm{C}$ (Yuan et al., 2008). Solvent displacement technique was used to prepare $\beta$-carotene nanodispersions of 30 $206 \mathrm{~nm}$ using emulsifiers such as sodium caseinate, Tween 20, decaglycerol monolaurate, and sucrose fatty acid ester. Though, starch casein stabilized nanodispersions had large particles size but they were most stable against oxidation. This might be due to physical barrier and the antioxidant activity of caseins (Yin et al., 2009). $\beta$-carotene nanoemulsions stabilized by modified starch and spray-dried to powders after the emulsification process had better storage stability. Modified starches having low film oxygen permeability had a high retention of betacarotene during storage (Liang et al., 2013). Physicochemical properties of $\beta$-carotene nanoemulsions have been improved by coating emulsions with starch caseinate and chitosanepigallocatechin-3-gallate conjugates (Wei and Gao, 2016). Sonication-assisted method with freeze drying has been used to prepare $\beta$-carotene nanoemulsions with high water dispersibility and chemical stability (Chen et al., 2017). Carotenoids were extracted from Cantaloupe melon. The nanoemulsions prepared from these carotenoids had improved water solubility and color stability. The o/w carotenoid nanoemulsions encapsulated in porcine gelatin and whey protein isolate had an average particle size of $70-160 \mathrm{~nm}$. Gelatin was able to increase water solubility of carotenoids. The yogurt containing these nanoemulsions as natural coloring agent was stable for 60 days (Medeiros et al., 2019).

\section{Encapsulation of Nutraceuticals}

Resveratrol, a natural polyphenol found in grape skins, blueberries, raspberries has many functional properties such as antioxidant, anticancer, and antiobesity. Nanoemulsions based delivery systems have been used to encapsulate resveratrol. Encapsulation of resveratrol by spontaneous emulsification using $10 \%$ oil phase (grape seed oil and orange oil), 10\% surfactant (Tween 80) and $80 \%$ aqueous phase had $100 \mathrm{~nm}$ droplet size and could carry $120 \pm 10 \mu \mathrm{g} / \mathrm{ml}$ of resveratrol. The encapsulated resveratrol had improved chemical stability against UV-light degradation (Davidov-Pardo and McClements, 2015). $\mathrm{O} / \mathrm{W}$ edible nanoemulsions of vitamin $\mathrm{D}$ (cholecalciferol) have been used for the fortification of dairy emulsions. Emulsifiers polysorbate 20 , soybean lecithin and their mixtures and dispersed oil phase of soybean oil or mixtures of the oil with cocoa butter were used to prepare nanoemulsions of mean diameters $<200 \mathrm{~nm}$ with high pressure homogenizer. Vitamin D3 $(0.1-0.5 \mu \mathrm{g} / \mathrm{mL})$ were encapsulated in the oil cores of stable nanoemulsions. Whole-fat milk was fortified with vitamin D3 nanoemulsions and were stable for 10 days against particle growth and gravitational separation (Golfomitsou et al., 2018). O/W nanoemulsions of kenaf seed oil stabilized with emulsifiers sodium caseinate, betacyclodextrin, and Tween 20 had improved in vitro bioaccessibility 
TABLE 3 | Functional compounds encapsulated into nanoemulsions for food applications.

\begin{tabular}{|c|c|c|c|c|c|}
\hline $\begin{array}{l}\text { Bioactive } \\
\text { compounds }\end{array}$ & Function & Method & Particle size & Constituents & Reference \\
\hline Citral & Flavoring agent & $\begin{array}{l}\mathrm{HPH}(6 \text { cycles for } 150 \mathrm{MPa}) \\
\mathrm{HPH}(6 \text { cycles/ } 150 \mathrm{MPa}) \\
\mathrm{HPH}(3 \text { cycles/1000 bar })\end{array}$ & $\begin{array}{l}109-129 \mathrm{~nm} \\
98-120 \mathrm{~nm} \\
467 \mathrm{~nm}\end{array}$ & $\begin{array}{l}\text { o/w : palm kernet fat/ citral/ undecane/ lecithin } \\
\text { aqueous buffer solution; } \\
\text { o/w: MCT/ buffer solution (citric acid/sodium } \\
\text { hydroxide/sodium chloride)/ soy lecithin/ citral/ } \\
\text { undecane } \\
\text { o/w: medium chain triacylglycerl/ buffer } \\
\text { solution (citric acid/sodium hydroxide/sodium } \\
\text { chloride)/ gelatin/ Tween 20/ citral/ undecane }\end{array}$ & $\begin{array}{l}\text { Yang et al., 2011, } \\
\text { Zhao et al., } 2013 \\
\text { Tian et al., } 2017\end{array}$ \\
\hline$\beta$-Carotene & Coloring agent & $\begin{array}{l}\text { Sequential HPH ( } 3 \text { cycles/ } \\
60-140 \mathrm{MPa}), \mathrm{MF} \text { and } \\
\text { Solvent-evaporation } \\
\text { Sequential HPH (140 MPa), } \\
\text { MF and Solvent-evaporation } \\
\text { MF (1-3 cycles/ } 140 \mathrm{MPa} \text { ) } \\
\text { HPH } \\
\text { SD } \\
\text { HPH (10 cycles/ } 150 \mathrm{MPa}) \\
\mathrm{HPH}(3 \text { cycles/ } 60 \mathrm{MPa}) \\
\text { Ultrasonication and MF } \\
\text { HPH }\end{array}$ & $\begin{array}{l}60-140 \mathrm{~nm} \\
85-132 \mathrm{~nm} \\
17-110 \mathrm{~nm} \\
132-184 \mathrm{~nm} \\
30-206 \mathrm{~nm} \\
114-159 \mathrm{~nm} \\
284 \mathrm{~nm} \\
230 \mathrm{~nm} \\
70-160 \mathrm{~nm}\end{array}$ & $\begin{array}{l}\text { o/w: Hexane/ } \beta \text {-carotene/ Tween } 20 \\
\text { o/w: Hexane/ } \beta \text {-carotene/ Polyglycerol } \\
\text { esters of monolaurate and monooleate; } \\
\text { o/w: Hexane/ } \beta \text {-carotene/ sodium caseinate/ } \\
\text { whey protein isolate/soy protein isolate } \\
\text { o/w: Hexane/ } \beta \text {-carotene/Tween } 20 \\
\text { o/w: Hexane/ } \beta \text {-carotene/starch/ } \\
\text { sodium caseinate/Tween } 20 / \text { decaglycerol } \\
\text { monolaurate/sucrose fatty acid ester } \\
\text { o/w: } \beta \text {-carotene/ } \\
\text { Starch/ medium chain triacylglycerl } \\
\text { o/w: } \beta \text {-carotene/ } \\
\text { sunflower oil/ starch } \\
\text { caseinate/chitosan-epigallocatechin-3-gallate } \\
\text { o/w: } \beta \text {-carotene/ } \\
\text { vegetable oil/ casein } \\
\text { o/w: Caotenoid extract/ soybean oil/gelatin/ } \\
\text { whey protein isolate }\end{array}$ & $\begin{array}{l}\text { Tan and Nakajima, } \\
2005 a \\
\text { Tan and Nakajima, } \\
2005 \text { b } \\
\text { Chu et al., } 2007 \\
\text { Yuan et al., } 2008 \\
\text { Yin et al., } 2009 \\
\text { Liang et al., } 2013 \\
\text { Wei and Gao, } \\
2016 \\
\text { Chen et al., } 2017 \\
\text { Medeiros et al., } \\
2019\end{array}$ \\
\hline Resveratrol & Nutraceutical & Spontaneous emulsification & $100 \mathrm{~nm}$ & $\begin{array}{l}\text { o/w: resveratrol/ grape seed oil/ Orange oil/ } \\
\text { Tween } 80\end{array}$ & $\begin{array}{l}\text { Davidov-Pardo } \\
\text { and McClements, } \\
2015\end{array}$ \\
\hline Vitamin D & Nutraceutical & $\mathrm{HPH}$ & $<200 \mathrm{~nm}$ & $\begin{array}{l}\text { o/w: Vitamin D/ polysorbate 20/ soybean } \\
\text { lecithin/ cocoa butter }\end{array}$ & $\begin{array}{l}\text { Golfomitsou et al., } \\
2018\end{array}$ \\
\hline Lecithin & Nutraceutical & MF (5 cycles/ 150 MPa) & $<400 \mathrm{~nm}$ & $\begin{array}{l}\text { o/w: curcumin/ corn oil/ sodium alginate/ } \\
\text { Tween } 20 / \text { lecithin }\end{array}$ & $\begin{array}{l}\text { Artiga-Artigas } \\
\text { et al., } 2018\end{array}$ \\
\hline \multirow[t]{2}{*}{ Oregano EO } & Preservative & Ultrasonication $(750 \mathrm{~W})$ & $148 \mathrm{~nm}$ & o/w: Oregano oil/Tween 80 & $\begin{array}{l}\text { Bhargava et al., } \\
2015 \text {, }\end{array}$ \\
\hline & & $\begin{array}{l}\text { Ultrasonication }(20 \mathrm{KHz} / 400 \\
\text { W/10 min) }\end{array}$ & $180-250 \mathrm{~nm}$ & $\begin{array}{l}\text { o/w: Oregano oil/ clove bud oil/Tween } 80 / \\
\text { distilled water }\end{array}$ & Otoni et al., 2014b \\
\hline Orange EO & Preservative & $\begin{array}{l}\text { Ultrasonication }(20 \mathrm{KHz} / 750 \\
\text { W/10 min) }\end{array}$ & $20-30 \mathrm{~nm}$ & o/w: orange oil/ Tween $80 /$ distilled water & $\begin{array}{l}\text { Sugumar et al., } \\
2015\end{array}$ \\
\hline Cinnamaldehyde & Preservative & Spontaneous emulsification & $20-500 \mathrm{~nm}$ & $\begin{array}{l}\text { o/w: Cinnamaldehyde/ Tween 80/ distilled } \\
\text { water }\end{array}$ & Otoni et al., $2014 a$ \\
\hline \multirow[t]{2}{*}{ Ginger EO } & Preservative & MF (10 cycles/1000 psi) & $133 \mathrm{~nm}$ & o/w: Ginger EO/ Tween 20/ Span 80/ Canola oil & $\begin{array}{l}\text { Acevedo Fani } \\
\text { et al., } 2015\end{array}$ \\
\hline & & $\begin{array}{l}\text { Ultrasonication }(20 \mathrm{KHz} / 200 \\
\text { W/ } 5 \mathrm{~min})\end{array}$ & $57 \mathrm{~nm}$ & o/w: Ginger EO/ Tween 80 & Noori et al., 2018 \\
\hline Curcumin & Preservative & Spontaneous emulsification & $40-130 \mathrm{~nm}$ & $\begin{array}{l}\text { o/w: Curcumin/ } \\
\text { Tween } 80 / \text { Glycerol/ Water }\end{array}$ & Abdou et al., 2018 \\
\hline $\begin{array}{l}\text { Capsaicin } \\
\text { (Capsicum } \\
\text { oleoresin) }\end{array}$ & Preservative & $\begin{array}{l}\mathrm{HPH}(5 \text { cycles/140 MPa) } \\
\text { Ultrasonication } \\
\text { ( } 75 \% \text { amplitude/ } 5 \mathrm{~min})\end{array}$ & $65 \mathrm{~nm}$ & o/w: Capsicum oleoresin/ Tween 80/ Water & Akbas et al., 2018 \\
\hline
\end{tabular}

HPH, High Pressure homogenization; MF, Microfluidization; MCT, medium chain triacylglycerl. 
and physicochemical stability of bioactive compounds and antioxidants. It was observed that after 8 weeks of storage at $4^{\circ} \mathrm{C}$, the nanoemulsions were stable and maintained antioxidant activities with high percentage retention of vitamin $\mathrm{E}$ and phytosterols (Cheong et al., 2018). Astaxanthin, a dietary supplement is a light sensitive molecule. Nanoemulsions have been formulated to photostabilize the pigment for its use in foods. The chitosan-coated and carrageenan-coated nanoemulsions of astaxanthin provided it protection from UV light and photodegradation (Alarcon-Alarcon et al., 2018).

Nanoemulsions have been used to improve the bioaccessibility of lipophilic bioactive compounds. Curcumin nanoemulsions prepared with chitosan and alginate had improved antioxidant capacity during in vitro digestion and a better control over lipid digestibility by decreasing free fatty acids. Thus, these nanoemulsions can be used to fortify functional foods for targeting obesity (Silva et al., 2018). Similarly, nanoemulsions of curcumin have been prepared with improved antioxidant capacity. Lecithin-stabilized nanoemulsions of curcumin had an encapsulation efficiency of $75 \%$ and were stable for 86 days in comparison to other surfactants such as Tween 20 stabilized curcumin nanoemulsions (Bhosale et al., 2014).

\section{Natural Preservatives}

Plant essential oils including thyme, oregano, clove and orange and their components such as thymol, carvacrol, eugenol, limonene, and cinnamon have strong antimicrobial activity against food borne pathogens. But their application in food matrix is limited due to their hydrophobicity. Nanoemulsion formulations of essential oils can be used to overcome this problem and they can be used in foods as natural preservatives and in food packaging (Alexandre et al., 2016).

Oregano oil nanoemulsions inhibited growth of foodborne bacteria Listeria monocytogenes, Salmonella Typhimurium and E. coli $\mathrm{O} 157: \mathrm{H7}$ on fresh lettuce. It was observed that oregano oil nanoemulsions disrupted bacterial membranes (Bhargava et al., 2015). Orange oil nanoemulsions inhibited spoilage of apple juice by Saccharomyces cerevisiae (Sugumar et al., 2015). Similarly, cinnamaldehyde nanoemulsions incorporated in pectin edible films inhibited growth of E. coli, Salmonella enterica, Listeria monocytogenes, and Staphylococcus aureus (Otoni et al., 2014a). Nanoemulsions of clove bud and oregano essential oil with $180-250 \mathrm{~nm}$ droplet size incorporated into edible methylcellulose films had improved antimicrobial activity. They prevented growth of yeasts and molds and improved shelf life of sliced bread (Otoni et al., 2014b). Nanoemulsions of ginger essential oil incorporated into gelatin-based films have shown to improve the physical properties of the active food packaging films (Alexandre et al., 2016). Curcumin nanoemulsions with mean droplet size of $40 \mathrm{~nm}$ pectin edible coatings increased the shelf life of chilled chicken at $4^{\circ} \mathrm{C}$ for 12 days. The nanoemulsion reduced microbial spoilage by inhibiting growth of psychrophiles, yeast and mold growth. Further, it showed reduced values of total volatile nitrogen and thiobarbituric acid, water holding capacity and texture and higher sensory scores in comparison to the control (Abdou et al., 2018). Nanoemulsions of ginger essential oil with sodium caseinate coating extended shelf life of chicken breast filet. The nanoemulsion based active coating had higher antibacterial activity than antioxidant activity. It reduced growth of psychrophilic bacteria in refrigerated chicken filets for 12 days (Noori et al., 2018). Nanoemulsions have been used to increase the bioavailability of lipophilic compounds. High pressure homogenization and ultrasoniction were used to prepare capsaicin (oleoresin capsicum) nanoemulsions with Tween 80 as the aqueous phase. Ultrasonication improved physical properties as nanoemulsions with particle size below $65 \mathrm{~nm}$ were obtained, whereas high pressure homogenization resulted in preparation of nanoemulsions with good inhibitory activity against $S$. aureus and E. coli (Akbas et al., 2018).

\section{NANOEMULSION BASED FOOD PACKAGING MATERIALS}

The nanoemulsions can be incorporated into films and coatings for potential food packaging applications. The films and coatings made up of biopolymer matrix constitute the continuous phase as they provide monodispersity and stability to nanoemulsion droplets. The increase in viscosity of the continuous phase reduces the coalescence of droplets (Artiga-Artigas et al., 2017). The preparation of nanoemulsion bioedible films includes dispersing the bioactive ingredients in a continuous phase which makes up the matrix of the packaging films. Food grade emulsions are added and appropriate high or low energy techniques are used for homogenization. The homogenized formulation is cast into films with controlled thickness and dried. Further, these films are characterized for the structural, morphological, thermal, mechanical, and barrier properties (Otoni et al., 2014a). The biopolymers used for film preparation also play a role in maintaining the functional properties of dispersed nanoemulsions.

The biopolymer pectin has been used to prepare edible films of cinnamaldehyde and clove essential oil nanoemulsions with antimicrobial properties. The pectin films had low water and vapor permeability due to the decrease in ratio of hydrophilic/hydrophobic (Otoni et al., 2014a; Sasaki et al., 2016). Cellulose and its derivatives have been used to prepare edible films containing nanoemulsions of clove and oregano essential oils (Otoni et al., 2014b). Chitosan has been used for preparation of nanoemulsion coatings and films of essential oils with antimicrobial activity such as carvacrol, mandarin oil, bergamot oil, and lemon oil (Severino et al., 2015). Sodium alginate was used to formulate films of nanoemulsion containing thyme, lemongrass, and sage essential oil (Acevedo Fani et al., 2015). It was also useful in preparing films containing small, stable and less size-dispersed nanoemulsions of corn oil (ArtigaArtigas et al., 2017). Porcine gelatin has been used in preparing films with antioxidant activity from canola oil and ginger essential oil nanoemulsions (Alexandre et al., 2016). It has also been used to prepare films of rutin-encapsulated soybean oil. However, the nanoemulsified essential oil increased the water vapor permeability values resulting in poor water barrier properties (Dammak et al., 2017). Basil seed gums have been 
used to prepare antimicrobial films of nano-emulsified Zataria multiflora essential oil (Gahruie et al., 2017).

The foods have also been immersed in nanoemulsions formulations to test their efficacy as coating agents without the aid of polymer matrix. Green beans have been coated with chitosan solution containing nanoemulsions of mandarin essential oil. And further irradiated with $\gamma$-irradiation, UV$\mathrm{C}$, and treated with ozonized water. The synergistic effect of the combined treatment of nanoemulsion coating and UV-C irradiation inhibited the growth of Listeria innocua in green beans (Severino et al., 2014). Sliced breads were immersed in methylcellulose-and clove bud or oregano essential oil nanoemulsions. There was a reduction in spoilage molds resulting in increase of shelf life of sliced bread (Otoni et al., 2014b). Fresh-cut Fuji apples have been immersed in nanoemulsion formulation of alginate-based edible coatings of lemongrass essential oil for $2 \mathrm{~min}$ and stored at $4^{\circ} \mathrm{C}$ for 14 days. The nanoemulsion coating had an inhibitory effect on E. coli and the growth of natural flora of apple was inhibited for 2 weeks (Salvia-Trujillo et al., 2015). Fresh-water rainbow trout was immersed for $15 \mathrm{~min}$ in the nanoemulsion formulation containing essential oils of Zataria multiflora Boiss and packaged within polyethylene bags and stored at $4^{\circ} \mathrm{C}$. Its shelf-life increased and sensory attributes were preserved during the storage time (Shadman et al., 2017). Similarly, rainbow trout filets immersed for $3 \mathrm{~min}$ in nanoemulsions of rosemary, laurel, thyme, and sage nanoemulsions were packed in stretch films and stored at $2^{\circ} \mathrm{C}$ for 24 days. The nanoemulsions were effective in inhibiting growth of psychrotrophs and and Enterobacteriaceae members (Ozogul et al., 2017). Spoilage of cherry tomatoes by molds such as Botritis cinerea has been prevented by coating it with thymol nanoemulsions. Quinoa protein and chitosan edible coating containing thymol nanoemulsion significantly inhibited growth of fungi on cherry tomatoes after 7 days when stored at $5^{\circ} \mathrm{C}$ (Robledo et al., 2018). Similarly, anise oil loaded nanoemulsions in comparison to coarse oil and bulk oil, significantly inhibited the growth of foodborne pathogens including E. coli O157:H7 and L. monocytogenes (Topuz et al., 2016).

\section{Nanoemulsions in Food Industry}

A number of in vitro and in vivo food challenge studies have shown the advantages of using nanoemulsions in foods as delivery systems for bioactive compounds. However, there are very limited examples of nanoemulsions of bioactive compounds incorporated into commercial food products or used as packaging materials. Nanoemulsions can be used for sustainable food processing. They can prevent the functional ingredients from temperature, oxidation, enzymatic reactions, and $\mathrm{pH}$ variations. Food industries such as Nestle and Unilever and a few Start-ups have used nanoemulsions in their food products (Silva et al., 2012; Salvia-Trujillo et al., 2017). Nestle have developed w/o nanoemulsions and patented polysorbates and micelle-forming emulsions for rapid and uniform thawing of frozen foods in the microwave (Möller et al., 2009). Unilever has used nanoemulsions in ice creams for reducing fat content from 16 to 1\% (Martins et al., 2007; Unilever, 2011). Novel nanoencapsulation method known as Nano-sized self assembled structured liquids (NSSL) have been developed by NutraLease, a technology start-up company. Small compressed micelles, called nanodrops are developed and these micelles serve as a carrier for fat soluble bioactives. The micelles incorporated in food products pass through the digestive system effectively and to the absorption sites without undergoing degradation. These nanoemulsions have been used for developing beverages with functional compounds. NutreLease with NSSL technology has fortified beverages with nanoemulsions of lipophilic compounds such as $\beta$-carotene, omega- 3 , vitamins, phytosterols, and isoflavones. It claimed that the food products had improved bioavailability and good shelf life (NutraLease, 2011). NSSL have been used by Shemen industries to develop Canola Active oil which is fortified with non-esterified phytosterols. The minute micelles carry the phytosterols to the large micelles that the body produces from the bile acid, where they compete with cholesterol for entry into the micelle. The phytosterols enter the micelle, thereby inhibiting transportation of cholesterol from the digestive system into the bloodstream. Similarly, Aquanova has developed NovaSol beverages fortified with nanoemulsions of functional compounds and natural colorants ( $\beta$-carotene, apocarotenal, chlorophyll, curcumin, lutein, and sweet pepper extract). It claimed that encapsulated compounds had enhanced stability and standardized additive concentrations (AquaNova, 2011). The product NovaSOL sustain contains nanocarrier that introduces coenzyme Q1O and alpha-lipoic acid. The micelle $(30 \mathrm{~nm})$ is stable to $\mathrm{pH}$ and temperature variations and is completely water soluble. The micelle is assumed to be optimum carrier system of lipophiles and can be used for efficient intestinal and dermal resorption and penetration of active ingredients (AquaNova, 2011). RBC Life sciences has developed NanoceuticalsTM Slim Shake Chocolate. It employs NanoCluster ${ }^{\mathrm{TM}}$ delivery system, a nanosize powder of nutritional supplements. CocoaClusters developed by this method is a technologically advanced form of cocoa and does not require sugar. During the process of creating NanoClusters, pure Cocoa is added to the "Cluster" formation. When consumed, it reduces the surface tension of foods and supplements to increase wetness and absorption of nutrients. Another nutritional supplement developed by RBC Life Sciences ${ }^{\circledR}$, is called NanoCeuticals ${ }^{\mathrm{TM}}$. The product NanoCeuticals ${ }^{\mathrm{TM}}$, with nanoscale ingredients is is claimed to have antioxidant properties. A product Nanotea developed by Shenzhen Become Industry \& Trade Co., Ltd. contains nanofine powder produced. The product is claimed to have antimicrobial activity and high selenium supplementation by 10 times. LivOn Labs has developed a product LypoSpheric ${ }^{\mathrm{TM}}$ Vitamin C which uses smart liposomal Nanospheres ${ }^{\circledR}$ to encapsulate Vitamin C. The product has increased the bioavailability of all nonliposome encapsulated forms of vitamin C (http://www.nanotechproject.org). Bottled waters with oilsoluble flavors and enriched with electrolytes, vitamins, and nutraceuticals with nanoemulsion technology have also been developed (Piorkowski and McClements, 2014).

Granalix BioTechnologies has commercially launched GranaGard $^{\mathrm{TM}}$ a food supplement based on pomegranate oil which has shown to prevent neurodegeneration diseases in animal models. GranaGard, is a submicron pomegranate seed oil 
emulsion, and is an innovative formulation containing natural antioxidants, Punicic acid (an Omega 5 lipid), which constitutes $80 \%$ of the nanoemuslion. The novel patented formulation was shown to delay disease onset and prevent neuronal death in animal models (Binyamin et al., 2015). Therapeutics Solutions International, Inc., has produced nutraceuticals prepared from NanoStilbene $e^{\mathrm{TM}}$, stable nanoemulsion of pterostilbene (75$90 \mathrm{~nm}$ ) from GRAS ingredients by low energy emulsification methods. The nanoemulsion of pterostilbene containing nanoparticles has been patented. Pterostilbene, the active ingredient in the Company's patented ProJuvenol product is a more potent analog of resveratrol. The nanoemulsions have a better solubility and stability than the parent compound (Dixon et al., 2017).

A flavor nanoemulsion containing a hydrophobic oil droplets containing flavors, an aqueous phase, and a surfactant system including a polyethoxylated sorbitan fatty acid ester and lecithin has been patented by International Flavors and Fragrances Inc. The flavor nanoemulsion has been used to prepare stable and optically clear liquid beverages including alcoholic beverages (Lee et al., 2015). Nanoemulsions of natural antioxidants (extracted from fruits, vegetables or cereals) for food preservative applications have been patented. The nanoemulsions of encapsulated natural antioxidants have been freeze dried and applied to preserve fresh and minimally processed foods. The nanoemulsion have been applied as thin, nanometre-size layer on the food. The nanoemulsion coating has been found to prevent gas and fluid exchange with the external environment. The edible nanocoatings extends the shelf life of fresh and minimally processed foods. It has also shown to improve the organoleptic quality of frozen foods on thawing (Malnati et al., 2019).

\section{CURRENT PERSPECTIVES AND FUTURE PROSPECTS}

In the last few years, a number of studies have been carried out to ascertain the advantages of encapsulation of lipophilic and functional compounds in nanoemulsions. Nanoemulsification is

\section{REFERENCES}

Abdou, E. S., Galhoum, G. F., and Mohamed, E. N. (2018). Curcumin loaded nanoemulsions/pectin coatings for refrigerated chicken fillets. Food Hydrocoll. 83, 445-453. doi: 10.1016/j.foodhyd.2018.05.026

Acevedo Fani, A., Salvia Trujillo, L., Rojas Graü, M. A., and Martín Belloso, O. (2015). Edible films from essential oil loaded nanoemulsions: Physicochemical characterization and antimicrobial properties. Food Hydrocoll. 47, 168-177. doi: 10.1016/j.foodhyd.2015.01.032

Acharya, D. P., and Hartley, P. G. (2012). Progress in microemulsion characterization. Curr. Opin. Colloid Interface Sci. 17, 274-280. doi: 10.1016/j.cocis.2012.07.002

Acosta, E. (2009). Bioavailability of nanoparticles in nutrient and nutraceutical delivery. Curr. Opin. Colloid Interface Sci. 14, 3-15. doi: $10.1016 /$ j.cocis.2008.01.002 known to protect and increase the bioavailability of bioactive compounds as shown by in vitro studies. But there are limited studies which show the actual health benefits of including nanoemulsions in foods, their consumption, labeling, and public perception. Similarly, studies have been carried out to evaluate the use of high or low energy approach to formulate nanoemulsions and the focus is on optimizing processing parameters and ingredients used in nanoemulsion preparation. But there is not much research on reducing the cost of production of nanoemulsions as its preparation and application for fortifying and packaging in foods require higher energy input and equipment investment. Similarly, the risks associated with the use of engineered nanoemulsions in foods is not known. The potential toxicological effects and biological fate of nanoparticles after digestion has not been elucidated.

Nanoemulsions of bioactive compounds and functional food ingredients have a great potential for applications in the food industries. The emulsion-based delivery systems and nanoemulsion edible coatings can improve the functionalities of food and also enhance their quality and shelf life. However, the food grade nanoemulsions can find widespread application only if its production cost is commercially feasible and meets the safety standards of food industry. Therefore, it is important to optimize the bioactivity of the encapsulated components for scaled up production. Further studies should focus on the biological events and risks associated with the use of nanoemulsion based delivery systems in food products and packaging applications for ensuring safety of the consumers.

\section{AUTHOR CONTRIBUTIONS}

JA and RV were involved in design, analysis, data collection, and preparation of the manuscript.

\section{ACKNOWLEDGMENTS}

The authors acknowledge the funding agency UGC-UPE, University of Mysore.
Akbas, E., Soyler, B., and Oztop, M. H. (2018). Formation of capsaicin loaded nanoemulsions with high pressure homogenization and ultrasonication. $L W T$. 96, 266-273. doi: 10.1016/j.lwt.2018.05.043

Alarcon-Alarcon, C., Inostroza-Riquelme, M., Torres-Gallegos, C., Araya, C., Miguel, M., Sanchez-Caamano, C., et al. (2018). Protection of astaxanthin from photodegradation by its inclusion in hierarchically assembled nano and microstructures with potential as food. Food Hydrocoll. 83, 36-44. doi: 10.1016/j.foodhyd.2018.04.033

Alexandre, E. M. C., Lourenço, R. V., Bittante, A. M. Q. B., Moraes, I. C. F., and Sobral, P. J. A. (2016). Gelatine based films reinforced with montmorillonite and activated with nanoemulsion of ginger essential oil for food packaging applications. Food Pack. Shelf Life. 10, 87-96. doi: 10.1016/j.fpsl.2016.10.004

Anton, N., Benoit, J.-P., and Saulnier, P. (2008). Design and production of nanoparticles formulated from nano-emulsion templates-a review. J. Control. Release 128, 185-199. doi: 10.1016/j.jconrel.2008.02.007 
Anton, N., and Vandamme, T. F. (2009). The universality of low-energy nanoemulsification. Int. J. Pharm. 377, 142-147. doi: 10.1016/j.ijpharm.2009.05.014

Anton, N., and Vandamme, T. F. (2011). Nano-emulsions and microemulsions: clarifications of the critical differences. Pharm. Res. 28, 978-985. doi: 10.1007/s11095-010-0309-1

AquaNova (2011). Available online at: http://www.aquanova.de/media/public/ pdf_produkte unkosher/NovaSOL_beverage (accessed May 10, 2019).

Artiga-Artigas, M., Acevedo-Fani, A., and Martín-Belloso, O. (2017). Effect of sodium alginate incorporation procedure on the physicochemical properties of nanoemulsions. Food Hydrocoll. 70, 191-200. doi: 10.1016/j.foodhyd.2017.04.006

Artiga-Artigas, M., Lanjari-Pérez, Y., and Martín-Belloso, O. (2018). Curcuminloaded nanoemulsions stability as affected by the nature and concentration of surfactant. Food Chem. 266, 466-474. doi: 10.1016/j.foodchem.2018.06.043

Azeredo, H., Mattoso, L. H. C., Wood, D., Williams, T. G., Avena-Bustillos, R. J., and McHugh, T. H. (2009). Nanocomposite edible films from mango puree reinforced with cellulose nanofibers. J. Food Sci. 74, 31-35. doi: 10.1111/j.1750-3841.2009.01186.x

Bae, D. H., Shin, J. S., Shin, G. S., Jin, F. L., and Park, S. J. (2009). Effect of lecithin on dermal safety of nanoemulsion prepared from hydrogenated lecithin and silicone oil. Bull. Korean Chem. Soc. 30, 821-824. doi: 10.5012/bkcs.2009.30.4.821

Bai, L., Huan, S., Gu, J., and McClements, D. J. (2016). Fabrication of oil-in-water nanoemulsions by dual-channel microfluidization using natural emulsifiers: Saponins, phospholipids, proteins, and polysaccharides. Food Hydrocoll. 61, 703-711. doi: 10.1016/.j.foodhyd.2016.06.035

Behrend, O., Ax, K., and Schubert, H. (2000). Influence of continuous phase viscosity on emulsification by ultrasound. Ultrason. Sonochem. 7, 77-85. doi: 10.1016/S1350-4177(99)00029-2

Bhargava, K., Conti, D. S., da Rocha, S. R. P., and Zhang, Y. (2015). Application of an oregano oil nanoemulsion to the control of foodborne bacteria on fresh lettuce. Food Microbiol. 47, 69-73. doi: 10.1016/j.fm.2014.11.007

Bhosale, R. R., Osmani, R. A., Ghodake, P. P., Shaikh, S. M., and Chavan, S. R. (2014). Nanoemulsion: a review on novel profusion in advanced drug delivery. Indian J. Pharm. Biol. Res. 2, 122-127. doi: 10.30750/ijpbr.2.1.19

Binyamin, O., Larush, L., Frid, K., Keller, G., Friedman-Levi, Y., Ovadia, H., et al. (2015). Treatment of a multiple sclerosis animal model by a novel nanodrop formulation of a natural antioxidant. Int. J. Nanomedicine 10, 7165-7174. doi: $10.2147 / \mathrm{IJN}$. S92704

Borthakur, P., Boruah, P. K., Sharma, B., and Das, M. R. (2016). Nanoemulsion: preparation and its application in food industry. Emulsions 3, 153-191. doi: 10.1016/B978-0-12-804306-6.00005-2

Bouchemal, K., Briançon, S., Perrier, E., and Fessi, H. (2004). Nano-emulsion formulation using spontaneous emulsification: solvent, oil and surfactant optimisation. Int. J. Pharm. 280, 241-251. doi: 10.1016/j.ijpharm.2004.05.016

Chen, J., Li, F., Li, Z., McClements, D. J., and Xiao, H. (2017). Encapsulation of carotenoids in emulsion-based delivery systems: enhancement of $\beta$ carotene water-dispersibility and chemical stability. Food Hydrocoll. 69, 49-55. doi: 10.1016/j.foodhyd.2017.01.024

Chen, L., Remondetto, G. E., and Subirade, M. (2006). Food protein-based materials as nutraceutical delivery systems. Trends Food Sci. Technol. 17, 272-283. doi: 10.1016/j.tifs.2005.12.011

Chen, Q.-H., Zheng, J., Xu, Y.-T., Yin, S.-W., Liu, F., and Tang, C.-H. (2018). Surface modification improves fabrication of pickering high internal phase emulsions stabilized by cellulose nanocrystals. Food Hydrocoll. 75, 125-130. doi: 10.1016/j.foodhyd.2017.09.005

Cheong, A. M., Tan, C. P., and Nyam, K. L. (2018). Stability of bioactive compounds and antioxidant activities of kenaf seed oil-in-water nanoemulsions under different storage temperatures. J. Food Sci. 83, 2457-2465. doi: $10.1111 / 1750-3841.14332$

Chu, B. S., Ichikawa, S., Kanafusa, S., and Nakajima, M. (2007). Preparation of proteinstabilized $\beta$-carotene nanodispersions by emulsification-evaporation method. J. Am. Oil Chem. Soc. 84, 1053-1062. doi: 10.1007/s11746-007-1132-7

Chuesiang, P., Siripatrawan, U., Sanguandeekul, R., McClements, D. J., and McLandsborough, L. (2019). Antimicrobial activity of PIT-fabricated cinnamon oil nanoemulsions: effect of surfactant concentration on morphology of foodborne pathogens. Food Control. 98, 405-411. doi: 10.1016/j.foodcont.2018.11.024

Chuesiang, P., Siripatrawan, U., Sanguandeekul, R., McLandsborough, L., and McClements, DJ. (2018). Optimization of cinnamon oil nanoemulsions using phase inversion temperature method: Impact of oil phase composition and surfactant concentration. J. Colloid Interface Sci. 514, 208-216. doi: 10.1016/j.jcis.2017.11.084

Dammak, I., de Carvalho, R. A., Trindade, C. S. F., Lourenço, R. V., and Sobral, P. J. A. (2017). Properties of active gelatin films incorporated with rutin-loaded nanoemulsions. Int. J. Biol. Macromol. 98, 39-49. doi: 10.1016/j.ijbiomac.2017.01.094

Date, A. A., Desai, N., Dixit, R., and Nagarsenker, M. (2010). Self-nanoemulsifying drug delivery systems: formulation insights, applications and advances. Nanomedicine 5, 1595-1616. doi: 10.2217/nnm.10.126

Davidov-Pardo, G., and McClements, D. J. (2015). Nutraceutical delivery systems: resveratrol encapsulation in grape seed oil nanoemulsions formed by spontaneous emulsification. Food Chem. 167, 205-212. doi: 10.1016/j.foodchem.2014.06.082

Dickinson, E. (1992). An Introduction to Food Colloids. 1st edn. Oxford; New York, NY; Tokyo: Oxford Science Publications.

Dixon, T. G., Berg, G. B., Graham, R. F., Kesari, S., and Ichim, T. (2017). Augmentation of Oncology Immunotherapies by Pterostilbene Containing Compositions. US Patent US9682047B2. June 20.

Donsi, F. (2018). "Applications of nanoemulsions in foods," in Nanoemulsions: Formulation, Applications, and Characterization, eds S. M. Jafari and D. J. McClements (Cambridge, MA: Academic Press), 349-377. doi: 10.1016/B978-0-12-811838-2.00011-4

Donsì, F., Ferrari, G., and Maresca, P. (2009). "High-pressure homogenization for food sanitization," in Global Issues in Food Science and Technology, eds G. V. Barbosa-Canovas, A. Mortimer, D. Lineback, W. Spiess, and K Buckle (Burlington, MA: Academic Press). doi: 10.1016/B978-0-12-374124-0.00019-3

Duffus, L. J., Norton, J. E., Smith, P., Norton, I. T., and Spyropoulos, F. (2016). A comparative study on the capacity of a range of food-grade particles to form stable O/W and W/O Pickering emulsions. J. Colloid Interface Sci. 473, 9-21. doi: 10.1016/j.jcis.2016.03.060

Ferreira, L. M., Cervi, V. F., Gehrcke, M., Da Silveira, E. F., Azambuja, J. H., Braganhol, E., et al. (2015). Ketoprofenloaded pomegranate seed oil nanoemulsion stabilized by pullulan: selective antiglioma formulation for intravenous administration. Colloids Surf. B Biointerfaces. 130, 272-277. doi: 10.1016/j.colsurfb.2015.04.023

Friberg, S., Larsson, K., and Sjoblom, J. (2004). Food Emulsions. New York, NY: Marcel Dekker. doi: 10.1201/9780203913222

Fryd, M. M., and Mason, T. G. (2012). Advanced nanoemulsions. Ann. Rev. Phys. Chem. 63, 493-518. doi: 10.1146/annurev-physchem-032210-103436

Gahruie, H. H., Ziaee, E., Eskandari, M. H., and Hosseini, S. M. H. (2017). Characterization of basil seed gum-based edible films incorporated with Zataria multiflora essential oil nanoemulsion. Carbohydr. Polym. 166, 93-103. doi: 10.1016/j.carbpol.2017.02.103

García-Márquez, E., Higuera-Ciapara, I., and Espinosa-Andrews, H. (2017). Design of fish oil-in-water nanoemulsion by microfluidization. Innov. Food Sci. Emerging. Technol. 40, 87-91. doi: 10.1016/j.ifset.2016.11.007

Garti, N., and Benichou, A. (2004). Recent developments in double emulsions for food applications. Food Emuls. 132, 353-412. doi: 10.1201/97802039132 22. $\operatorname{ch} 10$

Genovese, D. B., Lozano, J. E., and Rao, M. A. (2007). The rheology of colloidal and noncolloidal food dispersions. J. Food Sci. 72, 11-20. doi: 10.1111/j.1750-3841.2006.00253.x

Ghosh, V., Mukherjee, A., and Chandrasekaran, N. (2013). Ultrasonic emulsification of food-grade nanoemulsion formulation and evaluation of its bactericidal activity. Ultrason. Sonochem. 20, 338-344. doi: 10.1016/j.ultsonch.2012.08.010

Glatter, O., and Glatter, I. (2013). Water-in-oil emulsions and methods for their preparation. EP2604253-A1. Available online at: https://patents.google.com/ patent/EP2790655B1/ru

Goindi, S., Kaur, A., Kaur, R., Kalra, A., and Chauhan, P. (2016). Nanoemulsions: an emerging technology in the food industry. Emulsions. 3, 651-688. doi: 10.1016/B978-0-12-804306-6.00019-2 
Goldstein, J., Newbury, D. E., Joy, D. C., Lyman, C. E., Echlin, P., Lifshin, E., et al. (2003). Scanning Electron Microscopy and X-ray Microanalysis.New York, NY: Springer. doi: 10.1007/978-1-4615-0215-9

Golfomitsou, I., Mitsou, E., Xenakis, A., and Papadimitriou, V. (2018). Development of food grade $\mathrm{O} / \mathrm{W}$ nanoemulsions as carriers of vitamin $\mathrm{D}$ for the fortification of emulsion based food matrices: a structural and activity study. J. Mol. Liquids. 268, 734-742. doi: 10.1016/j.molliq.2018.07.109

Gradzielski, M. (2008). Recent developments in the characterisation of microemulsions. Curr. Opin. Colloid. Interface Sci. 13, 263-269. doi: 10.1016/j.cocis.2007.10.006

Guha, I. F., Anand, S., and Varanasi, K. K. (2017). Recent patents and innovations in food grade nanoemulsion developments. Nat. Commun. 8:1371. doi: 10.1038/s41467-017-01420-8

Gutiérrez, J. M., González, C., Maestro, A., Solè, I., Pey, C. M., and Nolla, J. (2008). Nano-emulsions: new applications and optimization of their preparation. Curr. Opin. Colloid Interface Sci. 13, 245-251. doi: 10.1016/j.cocis.2008.01.005

Guttoff, M., Saberi, A. H., and McClements, D. J. (2015). Formation of vitamin D nanoemulsion-based delivery systems by spontaneous emulsification: factors affecting particle size and stability. Food Chem. 171, 117-122. doi: 10.1016/j.foodchem.2014.08.087

Håkansson, A. (2019). Can high-pressure homogenization cause thermal degradation to nutrients? J. Food Eng. 240, 133-144. doi: 10.1016/j.jfoodeng.2018.07.024

Hathout, R. M., and Woodman, T. J. (2012). Applications of NMR in the characterization of pharmaceutical microemulsions. J. Control. Release 161, 62-72. doi: 10.1016/j.jconrel.2012.04.032

Hebishy, E., Buffa, M., Guamis, B., Blasco Moreno, G., and Trujillo, A. J. (2015). Physical and oxidative stability of whey protein oil-in-water emulsions produced by conventional and ultra high-pressure homogenization: effects of pressure and protein concentration on emulsion characteristics. Innov. Food Sci. Emerg. Technol. 32, 79-90. doi: 10.1016/j.ifset.2015.09.013

Howe, A. M., and Pitt, A. R. (2008). Rheology and stability of oil-in-water nanoemulsions stabilised by anionic surfactant and gelatin 1) addition of nonionic, cationic and ethoxylated-cationic co-surfactants. Adv. Colloid Interface Sci. 144, 24-29. doi: 10.1016/j.cis.2008.08.003

Imeson, A. (2011). Food Stabilisers, Thickeners and Gelling Agents. John Wiley \& Sons.

Ines, G. R. M., Juliana, M. C., Araceli, O. M., Laura, S. T., and Olga, M. B. (2015). Long-term stability of food-grade nanoemulsions from high methoxyl pectin containing essential oils. Food Hydrocoll. 52, 438-446. doi: 10.1016/j.foodhyd.2015.07.017

Inugala, S., Eedara, B. B., Sunkavalli, S., Dhurke, R., Kandadi, P., Jukanti, R., et al. (2015). Solid self-nanoemulsifying drug delivery system (S-SNEDDS) of darunavir for improved dissolution and oral bioavailability: in vitro and in vivo evaluation. Eur. J. Pharm. Sci. 74, 1-10. doi: 10.1016/j.ejps.2015. 03.024

Jafari, S., He, Y., and Bhandari, B. (2007). Optimization of nano-emulsions production by microfluidization. Eur. Food Res. Technol. 225, 733-741. doi: 10.1007/s00217-006-0476-9

Jafari, S. M., Assadpoor, E., He, Y. H., and Bhandari, B. (2008). Re-coalescence of emulsion droplets during high-energy emulsification. Food Hydrocoll. 22, 1191-1202. doi: 10.1016/j.foodhyd.2007.09.006

Jin, W., Xu, W., Liang, H., Li, Y., Liu, S., and Li, B. (2016). Nanoemulsions for food: properties, production, characterization, and applications. Emulsions 3, 1-36. doi: 10.1016/B978-0-12-804306-6.00001-5

Kabalnov, A. (2001). Ostwald ripening and related phenomena. J. Dispersion Sci. Technol. 22, 1-12. doi: 10.1081/DIS-100102675

Kabalnov, A. S., and Shchukin, E. D. (1992). Ostwald ripening theory: applications to fluorocarbon emulsion stability. Adv. Colloid Interface Sci. 38, 69-97. doi: 10.1016/0001-8686(92)80043-W

Kamogawa, K., Okudaira, G., Matsumoto, T., Sakai, H., and Abe, M. (2004). Preparation of oleic acid/water emulsions in surfactant-free condition by sequential processing using midsonic megasonic waves. Langmuir. 20, 2043-2047. doi: 10.1021/la030160z

Kang, D. J., Bararnia, H., and Anand, S. (2018). Synthesizing pickering nanoemulsions by vapor condensation. ACS Appl. Mater. Interfaces. 10, 21746-21754. doi: 10.1021/acsami.8b06467
Kentish, S., Wooster, T., Ashokkumar, M., Balachandran, S., Mawson, R., and Simons, L. (2008). The use of ultrasonics for nanoemulsion preparation. Innov. Food Sci. Emerg. Technol. 9, 170-175. doi: 10.1016/j.ifset.2007.07.005

Komaiko, J. S., and McClements, D. J. (2016). Formation of food-grade nanoemulsions using low-energy preparation methods: a review of available methods. Comprehens. Rev. Food Sci. Safety. 15, 331-352. doi: 10.1111/1541-4337.12189

Kralova, I., and Sjöblom, J. (2009). Surfactants used in food industry: a review. J. Dispersion Sci. Technol. 30, 1363-1383. doi: 10.1080/019326909027 35561

Krauel, K., Girvan, L., Hook, S., and Rades, T. (2007). Characterisation of colloidal drug delivery systems from the naked eye to Cryo-FESEM. Micron. 38, 796-803. doi: 10.1016/j.micron.2007.06.008

Kumar, R., Kaur, K., Uppal, S., and Mehta, S. K. (2017). Ultrasound processed nanoemulsion: a comparative approach between resveratrol and resveratrol cyclodextrin inclusion complex to study its binding interactions, antioxidant activity and uv light stability. Ultrason. Sonochem. 37, 478-489. doi: 10.1016/j.ultsonch.2017.02.004

Lee, D. K., Wang, C-F., Yang, Y., and Vaccari, D. (2015). International Flavors and Fragrances Inc., Flavor Nanoemulsions and Methods of Preparing the Same. US Patent PCT/US20 15/056470, WO2016064883A1. Available online at: https:// patents.google.com/patent/WO2016064883A1/en

Lee, L. L., Niknafs, N., Hancocks, R. D., and Norton, I. T. (2013). Emulsification: mechanistic understanding. Trends Food Sci. Technol. 31, 72-78. doi: 10.1016/j.tifs.2012.08.006

Lee, S. J., and McClements, D. J. (2010). Fabrication of protein-stabilized nanoemulsions using a combined homogenization and amphiphilic solvent dissolution/evaporation approach. Food Hydrocoll. 24, 560-569. doi: 10.1016/j.foodhyd.2010.02.002

Leong, T. S. H., Wooster, T. J., Kentish, S. E., and Ashokkumar, M. (2009). Minimising oil droplet size using ultrasonic emulsification. Ultrason. Sonochem. 16, 721-727. doi: 10.1016/j.ultsonch.2009.02.008

Li, X., Xing, Y., Jiang, Y., Ding, Y., and Li, W. (2009). Antimicrobial activities of $\mathrm{ZnO}$ powder-coated PVC film to inactivate food pathogens. Int. J. Food Sci. Technol. 44, 2161-2168. doi: 10.1111/j.1365-2621.2009. 02055.x

Liang, R., Huang, Q., Ma, J., Shoemaker, C. F., and Zhong, F. (2013). Effect of relative humidity on the store stability of spraydried beta-carotene nanoemulsions. Food Hydrocoll. 33, 225-233. doi: 10.1016/j.foodhyd.2013.03.015

Liew, J. C. L., Nguyen, Q. D., and Ngothai, Y. (2010). Effect of sodium chloride on the formation and stability of n-dodecane nanoemulsions by the PIT method. Asia Pac. J. Chem. Eng. 5, 570-576. doi: 10.1002/apj.445

Liu, J., Bi, J., Liu, X., Zhang, B., Wu, X., Wellala, C. K. D., et al. (2019). Effects of high pressure homogenization and addition of oil on the carotenoid bioaccessibility of carrot juice. Food Function 10, 458-468. doi: $10.1039 / \mathrm{C} 8 \mathrm{FO} 01925 \mathrm{H}$

Luo, X., Zhou, Y., Bai, L., Liu, F., and McClements, D. J. (2017). Fabrication of $\beta$-carotene nanoemulsion-based delivery systems using dual-channel microfluidization: physical and chemical stability. J. Colloid Interface Sci. 490, 328-335. doi: 10.1016/j.jcis.2016.11.057

Luykx, D. M., Peters, R. J., Van Ruth, S. M., and Bouwmeester, H. (2008). A review of analytical methods for the identification and characterization of nano delivery systems in food. J. Agric. Food Chem. 56, 8231-8247. doi: $10.1021 /$ jf8013926

Maali, A., and Hamed Mosavian, M. T. (2013), Preparation and application of nanoemulsions in the last decade (2000-2010). J. Dispers. Sci Tech. 34, 92-105. doi: 10.1080/01932691.2011.648498

Maestro, I., Sole, C., Gonzalez, C., Solans, C., and Gutierrez, J. M. (2008). Influence of the phase behavior on the properties of ionic nanoemulsions prepared by the phase inversion composition method. Colloid Interface Sci. 327, 433-439. doi: 10.1016/j.jcis.2008.07.059

Malnati, R. M. E. J., Du-Pont, M. X. A., and Morales, D. A. O. (2019). Method for Producing a Nanoemulsion With Encapsulated Natural Antioxidants for Preserving Fresh and Minimally Processed Foods, and the Nanoemulsion thus Produced. WIPO WO2019039947A1. Available online at: https://patentscope. wipo.int/search/en/detail.jsf?docId=WO2019039947 
Mao, L., Yang, J., Xu, D., Yuan, F., and Gao, Y. (2010). Effects of homogenization models and emulsifiers on the physicochemical properties of b-carotene nanoemulsions. J. Dispers. Sci. Technol. 31, 986-993. doi: 10.1080/01932690903 224482

Martins, P., Dulley, R., Ramos, S., Barbosa, M., Assumpção, R., Junior, S., et al. (2007). Nanotecnologias na Indústria de Alimentos. Available online at: http://www.pucsp.br/eitt/downloads/vi_ciclo_ paulomartinsuscoremarisabarbosa_nano__puc.pdf (accessed May 10, 2019).

Mason, T. G., Wilking, J. N., Meleson, K., Chang, C. B., and Graves, S. M. (2006). Nanoemulsions: formation, structure, and physical properties. J. Phys. Condens. Matter. 18:079001. doi: 10.1088/0953-8984/18/41/R01

Mayer, S., Weiss, J., and McClements, D. J. (2013). Vitamin E-enriched nanoemulsions formed by emulsion phase inversion: factors influencing droplet size and stability. J. Colloid Interface Sci. 402, 122-130. doi: 10.1016/j.jcis.2013.04.016

McClements, D. (2005). Food Emulsions: Principles, Practice, and Techniques, 2nd Edn. Boca Raton, FL: CRC.

McClements, D. J. (2004). Food Emulsions: Principles, Practices, and Techniques. Boca Raton, FL: CRC Press.

Mcclements, D. J. (2007). Critical review of techniques and methodologies for characterization of emulsion stability. Crit. Rev. Food Sci. Nutr. 47, 611-649. doi: 10.1080/10408390701289292

McClements, D. J., Decker, E. A., and Weiss, J. (2007). Emulsion-based delivery systems for lipophilic bioactive components. J. Food Sci. 72, 109-124. doi: 10.1111/j.1750-3841.2007.00507.x

McClements, D. J., and Li, Y. (2010). Review of in vitro digestion models for rapid screening of emulsion-based systems. Food Funct. 1, 32-59. doi: $10.1039 / \mathrm{c} 0$ fo00111b

McClements, D. J., and Rao, J. (2011). Food-grade nanoemulsions: formulation, fabrication, properties, performance, biological fate, and potential toxicity. Crit. Rev. Food Sci. Nutr. 51, 285-330. doi: 10.1080/10408398.2011.559558

Medeiros, A. K. O. C., Gomes, C. C., Amaral, M. L. Q. A., Medeiros, L. D. G., Medeiros, I., Porto, D. L., Aragão, C. F. S., et al. (2019). Nanoencapsulation improved water solubility and color stability of carotenoids extracted from Cantaloupe melon (Cucumis melo L.). Food Chem. 270, 562-572. doi: 10.1016/j.foodchem.2018.07.099

Mohanraj, V., and Chen, Y. (2007). Nanoparticles-a review. Trop. J. Pharm. Res. 5, 561-573. doi: 10.4314/tjpr.v5i1.14634

Möller, M., Eberle, U., Hermann, A., Moch, K., and Stratmann, B. (2009). Nanotechnology in the Food Sector. Zürich: TA-SWISS.

Nakabayashi, K., Amemiya, F., Fuchigami, T., Machida, K., Takeda, S., Tamamitsub, K., et al. (2011). Highly clear and transparent nanoemulsion preparation under surfactant-free conditions using tandem acoustic emulsification. Chem. Commun. 47, 5765-5767. doi: 10.1039/c1cc10558b

Nantarat, T., Chansakaow, S., and Leelapornpisid, P. (2015). Optimization, characterization and stability of essential oils blend loaded nanoemulsions by PIC technique for anti-tyrosinase activity. Int. J. Pharm. Pharm. Sci. 7, 308-312.

Noori, S., Zeynali, F., and Almasi, H. (2018). Antimicrobial and antioxidant efficiency of nanoemulsion-based edible coating containing ginger (Zingiber officinale) essential oil and its effect on safety and quality attributes of chicken breast fillets. Food Control. 84, 312-320. doi: 10.1016/j.foodcont.2017.08.015

NutraLease (2011). Available online at: http://www.nutralease.com/Nutra/ Templates $/$ showpage.asp?DBID $=1 \&$ LNGID $=1 \&$ TMID $=84 \&$ FID $=768$ (accessed May 10, 2019).

Otoni, C. G., de Moura, M. R., Aouada, F. A., Camilloto, G. P., Cruz, R. S., Lorevice, M. V., et al. (2014a). Antimicrobial and physicalmechanical properties of pectin/papaya puree/cinnamaldehyde nanoemulsion edible composite films. Food Hydrocoll. 41, 188-194. doi: 10.1016/j.foodhyd.2014.04.013

Otoni, C. G., Pontes, S. F., Medeiros, E. A., and Soares, N. de.F. (2014b). Edible films from methylcellulose and nanoemulsions of clove bud (Syzygium aromaticum) and oregano (Origanum vulgare) essential oils as shelf life extenders for sliced bread. J. Agric. Food Chem. 62, 5214-5219. doi: $10.1021 /$ jf501055f

Ozogul, Y., Yuvka, I., Ucar, Y., Durmus, M., Kösker, A. R., Öz, M., et al. (2017). Evaluation of effects of nanoemulsion based on herb essential oils (rosemary, laurel, thyme and sage) on sensory, chemical and microbiological quality of rainbow trout (Oncorhynchus mykiss) fillets during ice storage. LWT Food Sci. Technol. 75, 677-684. doi: 10.1016/j.lwt.2016.10.009
Pathak, M. (2017). Nanoemulsions and their stability for enhancing functional properties of food ingredients. Nanotechnol. Appl. Food 2017, 87-106. doi: 10.1016/B978-0-12-811942-6.00005-4

Piorkowski, D. T., and McClements, D. J. (2014). Beverage emulsions: recent developments in formulation, production, and applications. Food Hydrocolloid. 42, 5-41. doi: 10.1016/j.foodhyd.2013.07.009

Preetz, C., Hauser, A., Hause, G., Kramer, A., and Mader, K. (2010). Application of atomic force microscopy and ultrasonic resonator technology on nanoscale: distinction of nanoemulsions from nanocapsules. Eur. J. Pharm. Sci. 39, 141-151. doi: 10.1016/j.ejps.2009.11.009

Qadir, A., Faiyazuddin, M. D., Talib Hussain, M. D., Alshammari, T. M., and Shakeel, F. (2016). Critical steps and energetics involved in a successful development of a stable nanoemulsion. J. Mol. Liq. 214, 7-18. doi: 10.1016/j.molliq.2015.11.050

Qian, C, and McClements, D. J. (2011). Formation of nanoemulsions stabilized by model food-grade emulsifiers using high-pressure homogenization: factors affecting particle size. Food Hydrocoll. 25, 1000-1008. doi: 10.1016/j.foodhyd.2010.09.017

Quemeda, D., and Berli, C. (2002). Energy of interaction in colloids and its implications in rheological modeling. Adv. Colloid Interface Sci. 26, 51-85. doi: 10.1016/S0001-8686(01)00093-8

Rafanan, R. R. (2013). Encapsulation through the use of emulsified microemulsions (theses and dissertations) Ryerson University, Digital Commons @ Ryerson. Available online at: https://digital.library.ryerson.ca

Rao, J. J., and McClements, D. J. (2010). Stabilization of phase inversion temperature nanoemulsions by surfactant displacement. J. Agric. Food Chem. 58, 7059-7066. doi: 10.1021/jf100990r

Rayner, M., Marku, D., Eriksson, M., Sjoo, M., Dejmek, P., and Wahlgren, M. (2014). Biomass-based particles for the formulation of Pickering type emulsions in food and topical applications. Colloids Surf. A 458, 48-62. doi: 10.1016/j.colsurfa.2014.03.053

Ricaurte, L., Perea-Flores, M. J., Martinez, A., and Quintanilla-Carvajal, M. X. (2016). Production of high-oleic palm oil nanoemulsions by high-shear homogenization (microfluidization). Innov. Food Sci. Emerg. Technol. 35, 75-85. doi: 10.1016/j.ifset.2016.04.004

Ridel, L., Bolzinger, M. A., Fessi, H., and Chevalier, Y. (2015). Nanopickering: pickering nanoemulsions stabilized by bare silica nanoparticles. J. Colloid Sci. Biotechnol. 4, 110-116. doi: 10.1166/jcsb.2015.1122

Robledo, N., Vera, P., López, L., Yazdani-Pedram, M., Tapia, C., and Abugoch, L. (2018). Thymol nanoemulsions incorporated in quinoa protein/chitosan edible films; antifungal effect in cherry tomatoes. Food Chem. 246, 211-219. doi: 10.1016/j.foodchem.2017.11.032

Rojas-Graü, M. A., Soliva-Fortuny, R., and Martín-Belloso, O. (2009). Edible coatings to incorporate active ingredients to fresh-cut fruits: a review. Trends Food Sci. Technol. 20, 438-447. doi: 10.1016/j.tifs.2009. 05.002

Ruiz-Montañez, G., Ragazzo-Sanchez, J. A., Picart-Palmade, L., CalderónSantoyo, M., and Chevalier-Lucia, D. (2017). Optimization of nanoemulsions processed by high-pressure homogenization to protect a bioactive extract of jackfruit (Artocarpus heterophyllus Lam). Innov. Food Sci. Emerg. Technol. 40, 35-41. doi: 10.1016/j.ifset.2016. 10.020

Saberi, A. H., Fang, Y., and McClements, D. J. (2013). Fabrication of vitamin E-enriched nanoemulsions: factors affecting particle size using spontaneous emulsification. J. Colloid Interface Sci. 391, 95-102. doi: 10.1016/j.jcis.2012.08.069

Saifullah, M., Ahsan, A., and Shishir, M. R. I. (2016). "Production, stability and application of micro- and nanoemulsion in food production and the food processing industry," in Nanotechnology in the Agri-Food Industry, Emulsions, ed A. M. Grumezescu (Cambridge, MA: Academic Press), 405-442. doi: 10.1016/B978-0-12-804306-6.00012-X

Salager, J. L., Forgiarini, A., Marquez, L., Pena, A., Pizzino, A., Rodriguez, M. P., et al. (2004). Using emulsion inversion in industrial processes. Adv. Colloid Interface Sci. 108, 259-272. doi: 10.1016/j.cis.2003.10.008

Salvia-Trujillo, L., Rojas-Graü, M. A., Soliva-Fortuny, R., and Martín-Belloso, O. (2015). Use of antimicrobial nanoemulsions as edible coatings: impact on safety and quality attributes of fresh-cut Fuji apples. Postharvest Biol. Technol. 105, 8-16. doi: 10.1016/j.postharvbio.2015.03.009 
Salvia-Trujillo, L., Soliva-Fortuny, R., Rojas-Graü, M. A., McClements, D. J., and Martín-Belloso, O. (2017). Edible nanoemulsions as carriers of active ingredients: A review. Annu. Rev. Food Sci. Technol. 8, 439-466. doi: 10.1146/annurev-food-030216-025908

Sasaki, R. S., Mattoso, L. H. C., and de Moura, M. R. (2016). New edible bionanocomposite prepared by pectin and clove essential oil nanoemulsions. J. Nanosci. Nanotechnol. 16, 6540-6544. doi: 10.1166/inn.2016.11702

Saxena, A., Maity, T., Paliwal, A., and Wadhwa, S. (2017). "Technological aspects of nanoemulsions and their applications in the food sector," in Nanotechnology Applications in Food (Cambridge, MA: Academic Press), 129152. doi: 10.1016/b978-0-12-811942-6.00007-8

Schramm, L. L. (2006). Interfacial Energetics. Emulsions, Foams, and Suspensions. Wiley-VCH Verlag GmbH \& Co. KGaA. 53-100. doi: 10.1002/3527606750.ch3

Schroder, A., Sprakel, J., Schroen, K., and Berton-Carabin, C. (2017). Tailored microstructure of colloidal lipid particles for pickering emulsions with tunable properties. Soft Matter 13, 3190-3198. doi: 10.1039/C6SM02432G

Schroder, A., Sprakel, J., Schroen, K., Spaen, N. J., and Berton-Carabin, C. (2018). Coalescence stability of Pickering emulsions produced with lipid particles: a microfluidic study. J. Food Eng. 234, 63-72. doi: 10.1016/j.jfoodeng.2018.04.007

Schubert, H., and Engel, R. (2004). Product and formulation engineering of emulsions. Chem. Eng. Res. Des. 82, 1137-1143. doi: $10.1205 /$ cerd.82.9.1137.44154

Schuch, A., Wrenger, J., and Schuchmann, H. P. (2014). Production of W/O/W double emulsions. Part II: influence of emulsification device on release of water by coalescence. Colloids Surf. A 461, 344-351. doi: 10.1016/j.colsurfa.2013.11.044

Schultz, S., Wagner, G., Urban, K., and Ulrich, J. (2004). High-pressure homogenization as a process for emulsion formation. Chem. Eng. Technol. 27, 361-368. doi: 10.1002/ceat.200406111

Severino, R., Ferrari, G., Vu, K. D., Donsi, F., Salmieri, S., and Lacroix, M. (2015). Antimicrobial effects of modified chitosan based coating containing nanoemulsion of essential oils, modified atmosphere packaging and gamma irradiation against Escherichia coli O157:H7 and Salmonella Typhimurium on green beans. Food Control. 50, 215-222. doi: 10.1016/j.foodcont.2014.08.029

Severino, R., Vu, K. D., Donsì, F., Salmieri, S., Ferrari, G., and Lacroix, M. (2014). Antibacterial and physical effects of modified chitosan based-coating containing nanoemulsion of mandarin essential oil and three non-thermal treatments against Listeria innocua in green beans. Int. J. Food Microbiol. 191, 82-88. doi: 10.1016/j.ijfoodmicro.2014.09.007

Shadman, S., Hosseini, S. E., Langroudi, H. E., and Shabani, S. (2017). Evaluation of the effect of a sunflower oil-based nanoemulsion with Zataria multiflora Boiss. essential oil on the physicochemical properties of rainbow trout (Oncorhynchus mykiss) fillets during cold storage. LWT Food Sci. Technol. 79, 511-517. doi: 10.1016/j.lwt.2016.01.073

Shahidi, F., and Zhong, Y. (2010). Lipid oxidation and improving the oxidative stability. Chem. Soc. Rev. 39, 4067-4079. doi: 10.1039/b922183m

Shakeel, F., Baboota, S., Ahuja, A., Ali, J., and Shafiq, S. (2009). Celecoxib nanoemulsion for transdermal drug delivery: characterization and in vitro evaluation. J. Dispers. Sci. Technol. 30, 834-842. doi: $10.1080 / 01932690802644012$

Shariffa, Y. N., Tan, T. B., Uthumporn, U., Abas, F., Mirhosseini, H., Nehdi, I. A., et al. (2017). Producing a lycopene nanodispersion: formulation development and the effects of high pressure homogenization. Food Res. Int. 101, 165-172. doi: 10.1016/j.foodres.2017.09.005

Sharma, G., Wilson, K., Van der walle, C., Sattar, N., Petrie, J., and Kumar, M. R. (2010). Microemulsions for oral delivery of insulin: design, development and evaluation in streptozotocin induced diabetic rats. Eur. J. Pharm. Biopharm. 76, 159-169. doi: 10.1016/j.ejpb.2010.07.002

Silva, H. D., Cerqueira, M. A., and Vicente, A. (2012). Nanoemulsions for food applications: development and characterization. Food Bioproc. Technol. 5, 854-867. doi: 10.1007/s11947-011-0683-7

Silva, H. D., Cerqueira, M. A., and Vicente, A. A. (2015). Influence of surfactant and processing conditions in the stability of oil-in-water nanoemulsions. J. Food Eng. 167, 89-98. doi: 10.1016/j.jfoodeng.2015.07.037

Silva, H. D., Poejo, J., Pinheiro, A. C., Donsi, F., and Vicente, A. A. (2018). Evaluating the behaviour of curcumin nanoemulsions and multilayer nanoemulsions during dynamic in vitro digestion. J. Functional Foods. 48, 605-613. doi: 10.1016/j.jff.2018.08.002
Sonneville-Aubrun, O., Simonnet, J. T., and L'alloret, F. (2004). Nanoemulsions: a new vehicle for skincare products. Adv. Colloid Interface Sci. 108, 145-149. doi: $10.1016 /$ j.cis.2003.10.026

Souto, E. B., Anselmi, C., Centini, M., and Muller, R. H. (2005). Preparation and characterization of n-dodecyl-ferulate-loaded solid lipid nanoparticles (SLN). Int. J. Pharm. 295, 261-268. doi: 10.1016/j.ijpharm.2005.02.005

Spernath, L., Regev, O., Levi-Kalisman, Y., and Magdassi, S. (2009). Phase transitions in $\mathrm{O} / \mathrm{W}$ lauryl acrylate emulsions during phase inversion, studied by light microscopy and cryo-TEM. Colloids Surf. A 332, 19-25. doi: 10.1016/j.colsurfa.2008.08.026

Stang, M., Schuchmann, H., and Schubert, H. (2001). Emulsification in high-pressure homogenizers. Eng. Life Sci. 1, 151-157. doi: 10.1002/1618-2863(200110)1:4<;151::AID-ELSC151>;3.0.CO;2-D

Sugumar, S., Singh, S., Mukherjee, A., and Chandrasekaran, N. (2015). Nanoemulsion of orange oil with non ionic surfactant produced emulsion using ultrasonication technique: evaluating against food spoilage yeast. Appl. Nanosci. 6, 113-120. doi: 10.1007/s13204-015-0412-z

Tabilo-Munizaga, G., Villalobos-Carvajal, R., Herrera-Lavados, C., MorenoOsorio, L., Jarpa-Parra, M., and Pérez-Won, M. (2019). Physicochemical properties of high-pressure treated lentil protein-based nanoemulsions. LWT. 101, 590-598. doi: 10.1016/j.lwt.2018.11.070

Tadros, T., Izquierdo, P., Esquena, J., and Solans, C. (2004). Formation and stability of nano-emulsions. Adv. Colloid Interface Sci. 108, 303-318. doi: $10.1016 /$ j.cis.2003.10.023

Tan, C. P., and Nakajima, M. (2005a). $\beta$-Carotene nanodispersions: preparation, characterization and stability evaluation. Food Chem. 92, 661-671. doi: 10.1016/j.foodchem.2004.08.044

Tan, C. P., and Nakajima, M. (2005b). Effect of polyglycerol esters of fatty acids on physicochemical properties and stability of $\beta$-carotene nanodispersions prepared by emulsification/evaporation method. J. Sci. Food Agric. 85, 121-126. doi: 10.1002/jsfa.1947

Tan, T. B., Yussof, N. S., Abas, F., Mirhosseini, H., Nehdi, I. A., and Tan, C. P. (2016). Comparing the formation of lutein nanodispersion prepared by using solvent displacement method and high-pressure valve homogenization: effects of formulation parameters. J. Food Eng. 177, 65-71. doi: 10.1016/j.jfoodeng.2015.12.020

Tesch, S., Freudig, B., and Schubert, H. (2003). Production of emulsions in highpressure homogenizers e part I: disruption and stabilization of droplets. Chem. Eng. Technol. 26, 569-573. doi: 10.1002/ceat.200390086

Thanasukarn, P., Pongsawatmanit, R., and Mcclements, D. (2004) Influence of emulsifier type on freeze-thaw stability of hydrogenated palm oil-in-water emulsions. Food Hydrocolloid. 18, 1033-1043. doi: 10.1016/j.foodhyd.2004.04.010

Tian, H., Li, D., Xu, T., Hu, J., Rong, Y., and Zhao, B. (2017). Citral stabilization and characterization of nanoemulsions stabilized by a mixture of gelatin and Tween 20 in an acidic system. J. Sci. Food Agric. 97, 2991-2998. doi: 10.1002/ jsfa.8139

Tian, W. L., Lei, L. L., Zhang, Q., and Li, Y. (2016). Physical stability and antimicrobial activity of encapsulated cinnamaldehyde by self-emulsifying nanoemulsion. J. Food Process Eng. 39, 462-471. doi: 10.1111/jfpe.12237

Topuz, O. K., Ozyural, E. B., Zhao, Q., Huang, Q., Chikindas, M., and Golukcu, M. (2016). Physical and antimicrobial properties of anise oil loaded nanoemulsions on the survival of foodborne pathogens. Food Chem. 203, 117-123. doi: 10.1016/j.foodchem.2016.02.051

Unilever (2011). Available online at: http://www.unilever.com/innovation/ productinnovations/coolicecreaminnovations/?WT.LHNAV=Cool_ice_ cream_innovations (accessed April 13, 2011).

Velikov, K. P., and Pelan, E. (2008). Colloidal delivery systems for micronutrients and nutraceuticals. Soft Matter. 4, 1964-1980. doi: 10.1039/b804863k

Walker, R. M., Decker, E. A., and McClements, D. J. (2015). Physical and oxidative stability of fish oil nanoemulsions produced by spontaneous emulsification: effect of surfactant concentration and particle size. J. Food Eng. 164, 10-20. doi: 10.1016/j.jfoodeng.2015.04.028

Walstra, P. (2003). Physical Chemistry of Foods.New York, NY: Marcel Decker. doi: $10.1201 / 9780203910436$

Wei, Z., and Gao, Y. (2016). Physicochemical properties of $\beta$-carotene bilayer emulsions coated by milk proteins and chitosan-EGCG conjugates. Food Hydrocoll. 52, 590-599. doi: 10.1016/j.foodhyd.2015.08.002 
Weiss, J., Takhistov, P., and McClements, D. J. (2006). Functional materials in food nanotechnology. J. Food Sci. 71, 107-116. doi: 10.1111/j.1750-3841.2006.00195.x

Windhab, E. J., Dressler, M., Feigl, K., Fischer, P., and Megias-Alguacil, D. (2005). Emulsion processingefrom single-drop deformation to design of complex processes and products. Chem. Eng. Sci. 60, 2101-2113. doi: 10.1016/j.ces.2004.12.003

Witthayapanyanon, A., Acosta, E. J., Harwell, J. H., and Sabatini, D. A. (2006). Formulation of ultralow interfacial tension systems using extended surfactants. J. Surfactants Deterg. 9, 331-339. doi: 10.1007/s11743-0065011-2

Wooster, T. J., Golding, M., and Sanguansri, P. (2008). Impact of oil type on nanoemulsion formation and Ostwald ripening stability. Langmuir ACS J. Surf. Colloids. 24, 12758-12765. doi: 10.1021/la801685v

Xianquan, S., Shi, J., Kakuda, Y., and Yueming, J. (2005). Stability of lycopene during food processing and storage. J. Med. Food. 8, 413-422. doi: 10.1089/jmf.2005.8.413

Yang, X., Tian, H., Ho, C. T., and Huang, Q. (2011). Inhibition of citral degradation by oilin-water nanoemulsions combined with antioxidants. J. Agric. Food Chem. 59, 6113-6119. doi: 10.1021/jf2012375

Yin, L. J., Chu, B. S., Kobayashi, I., and Nakajima, M. (2009). Performance of selected emulsifiers and their combinations in the preparation of $\beta$-carotene nanodispersions. Food Hydrocoll. 23, 1617-1622. doi: 10.1016/j.foodhyd.2008.12.005
Yuan, Y., Gao, Y., Zhao, J., and Mao, L. (2008). Characterization and stability evaluation of $\beta$-carotene nanoemulsions prepared by high pressure homogenization under various emulsifying conditions. Food Res. Int. 41, 61-68. doi: 10.1016/j.foodres.2007. 09.006

Yun Zhang, P. G. W. (2003). Studying the interaction of gel carbohydrate antigen and protein by quartz-crystal microbalance. J. Am. Chem. Soc. 125, 9292-9293. doi: 10.1021/ja035350a

Zhao, Q., Ho, C. T., and Huang, Q. (2013). Effect of ubiquinol-10 on citral stability and off-flavor formation in oil-in-water (o/w) nanoemulsions. J. Agric. Food Chem. 61, 7462-7469. doi: 10.1021/jf40 17527

Conflict of Interest: The authors declare that the research was conducted in the absence of any commercial or financial relationships that could be construed as a potential conflict of interest.

Copyright (c) 2019 Aswathanarayan and Vittal. This is an open-access article distributed under the terms of the Creative Commons Attribution License (CC BY). The use, distribution or reproduction in other forums is permitted, provided the original author(s) and the copyright owner(s) are credited and that the original publication in this journal is cited, in accordance with accepted academic practice. No use, distribution or reproduction is permitted which does not comply with these terms. 